University of Louisville

ThinkIR: The University of Louisville's Institutional Repository

Electronic Theses and Dissertations

8-2017

\title{
Controlled electrochemical synthesis of single one-dimensional metal nanochains across microgap electrodes.
}

Amareshwari Konutham

University of Louisville

Follow this and additional works at: https://ir.library.louisville.edu/etd

Part of the Analytical Chemistry Commons, Inorganic Chemistry Commons, Materials Chemistry Commons, Other Chemistry Commons, and the Physical Chemistry Commons

\section{Recommended Citation}

Konutham, Amareshwari, "Controlled electrochemical synthesis of single one-dimensional metal nanochains across microgap electrodes." (2017). Electronic Theses and Dissertations. Paper 2797. https://doi.org/10.18297/etd/2797

This Master's Thesis is brought to you for free and open access by ThinkIR: The University of Louisville's Institutional Repository. It has been accepted for inclusion in Electronic Theses and Dissertations by an authorized administrator of ThinkIR: The University of Louisville's Institutional Repository. This title appears here courtesy of the author, who has retained all other copyrights. For more information, please contact thinkir@louisville.edu. 
CONTROLLED ELECTROCHEMICAL SYNTHESIS OF SINGLE ONE-

DIMENSIONAL METAL NANOCHAINS ACROSS MICROGAP

ELECTRODES

By

Amareshwari Konutham

B.S. Osmania University,

M.Sc., Jawaharlal Technological University Hyderabad,

A Thesis

Submitted to the Faculty of the

College of Arts and Science of the University of Louisville

In Partial Fulfillment of the Requirements for the Degree of

Master of Science in Chemistry

Department of Chemistry

University of Louisville

Louisville, Kentucky.

August, 2017 
Copyright 2017 by Amareshwari Konutham

All rights reserved 

CONTROLLED ELECTROCHEMICAL SYNTHESIS OF SINGLE ONEDIMENSIONAL METAL NANOCHAINS ACROSS MICROGAP ELECTRODES

By

Amareshwari Konutham

A Thesis Approved on

August $3 \square 2017$

by the following Thesis Committee

\begin{tabular}{c}
\hline $\begin{array}{c}\text { Dr. Francis P. Zamborini } \\
\text { (Thesis Director) }\end{array}$ \\
\hline
\end{tabular}

Dr. Craig A. Grapperhaus

Dr. Richard P. Baldwin

Dr. Martin O'Toole 


\section{DEDICATION}

This thesis is dedicated to my grandparents

Shri Satyanarayana and Smt. Late Anasuya 


\section{ACKNOWLEDGEMENTS}

I would like to express my sincere gratitude to my advisor $\mathrm{Dr}$. Francis $\mathrm{P}$. Zamborini for the motivation, encouragement, patience and continuous support of my research. His immense knowledge and motivation helped me in all the time of research and writing of this thesis. Without his guidance and persistent help this thesis would not have been possible. I must mention that working under him helped me to become a better person.

I would like to thank the committee members Dr. Richard P. Baldwin, Dr. Craig A. Grapperhaus and Dr. Martin O'Toole for taking time and giving their valuable suggestions. I would like to thank Aaron Howell, Sherry Nalley and Sabrina for their support with ordering and administration work. I'm very thankful to Renu Kakar and Luther Benjamin Hutcherson for the stockroom supplies. Steve Riley has provided excellent support with the instrumentation and he would just make any instrument work with his skills.

I also thank my group members Dr. Nidhi Shah, Shekhar Bhama, Stacy Allen, Dhruba Pattadar, Tirtha Sibakoti, Badri Manali, Jay Sharma \& Pom Kharel. Dr. Nidhi Shah was very helpful from the time I joined the research group. She trained me on all of the instruments and continued her support even after her graduation. 
A special word of thanks to my parents Konutham Sudarshan and Konutham Annapurna for their continuous unparalleled love and continuous encouragement. I would like to thank my parents for allowing me to realize my own potential. I am grateful to my husband Sravan Kumar Vanguru for always being there for me. This journey would not have been possible if not for them.

Finally, I would like to thank the University of Louisville for letting me fulfill my dream of being a student here and providing me with a Graduate Teaching Assistantship. 


\section{ABSTRACT \\ CONTROLLED ELECTROCHEMICAL SYNTHESIS OF SINGLE ONE- DIMENSIONAL METAL NANOCHAINS ACROSS MICROGAP ELECTRODES \\ Amareshwari Konutham}

August 3,2017

This study mainly focuses on the fabrication of single one dimensional (1D) NP chains across the 5-micron gap of Au two electrode devices (TED). This has been achieved by electrochemical deposition of $\mathrm{Ag}$ onto the two electrodes, soaking the TED in $0.1 \mathrm{M}$ Cetyltrimethyl ammonium bromide for 2-3 hours, and then close monitoring of the current as a function of time while a voltage across the two Ag coated Au electrodes in air. One dimensional Ag nanoparticle chain formation occurred by oxidation of $\mathrm{Ag}$ to $\mathrm{Ag}^{+}$at the positive electrode followed by movement of $\mathrm{Ag}^{+}$ions to the negative electrode and deposition by reduction of $\mathrm{Ag}^{+}$. Chain formation could be detected by current spike in a current time plot at a specific voltage. High voltage of 3-5 V and the appearance of multiple spikes led to several chains across the gap with uncontrolled current. We fabricated single 1D nano chains by applying a voltage of $1 \mathrm{~V}$ across the $\mathrm{Ag}$ deposited TEDs for 1000 seconds. If no current spikes appeared, we went to $2 \mathrm{~V}$ for $1000 \mathrm{~s}$, and so on until the first appearance at a current spike. After the first spike appeared, we then stopped the voltage and went to $1 \mathrm{~V}$ for a certain amount of time until the current reached the desired level. This led to single nanoparticle chains with 
controlled resistance values ranging from 0.1 to $10 \mathrm{~s}$ of kilo ohms. The chain morphology chained dramatically depending on the resistance of the chain and the Ag deposition method. Chains formed from the electrodeposited Ag nanoneedles displayed chains of Ag nanoparticles well-aligned single file at high resistance and more continuous rods/wire at low resistance. Chains formed from electrodeposited Ag nanoneedles displayed chains of Ag nanoparticles well-aligned single file at high resistance and more continuous rods/wire at low resistance. Chains formed from electrodeposited Ag NP films display a cone shape with wide base at positive electrode and more narrow chain at the negative electrode, especially for higher resistance wires. 


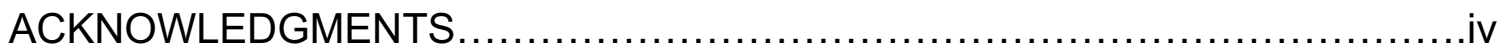

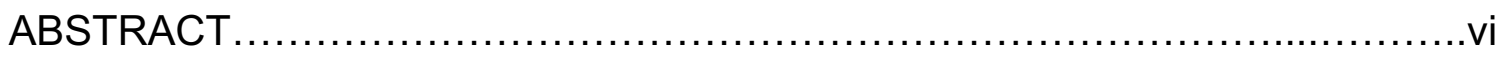

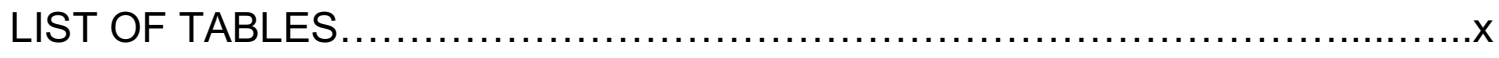

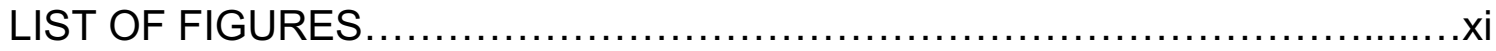

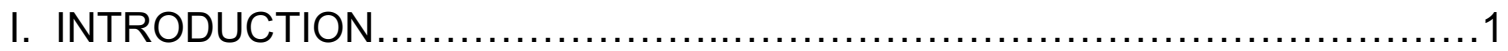

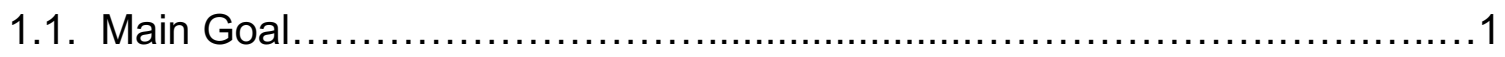

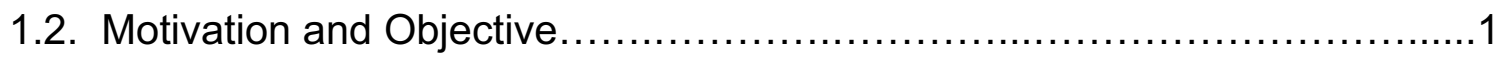

1.3. Nanostructures and Their Importance........................................

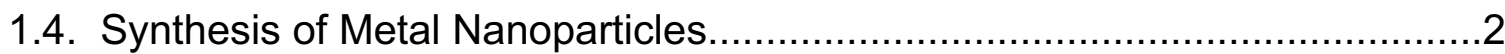

1.5. Assembly of Metal Nanoparticles into 1D Chains.........................................

1.5.1. 1D Metal NP Assembly by Lithography ............................................

1.5.2. Template-Directed Assembly of 1D Metal NPs......................................

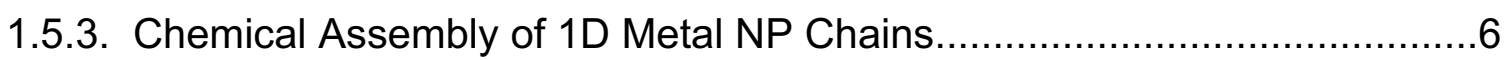

1.6. Assembly of Metal Nanoparticles between Electrode Gaps.........................

1.7. Application of 1D Nanoparticle Chains..................................................11

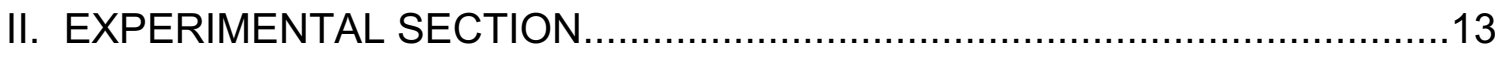

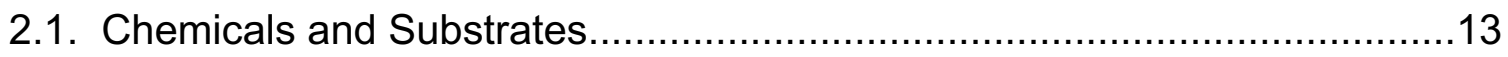

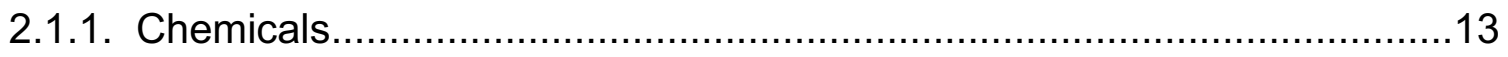

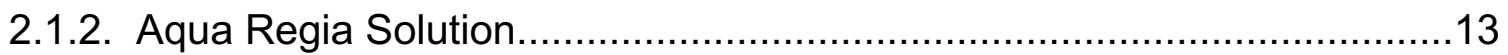


2.1.3. Microfabrication of Au Two Electrode Devices (TED) on $\mathrm{Si} / \mathrm{SiO}_{2}$

2.1.4. Cleaning and Wiring of Au Two Electrode Devices.

2.2. Techniques.

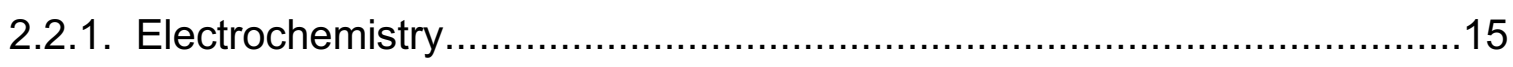

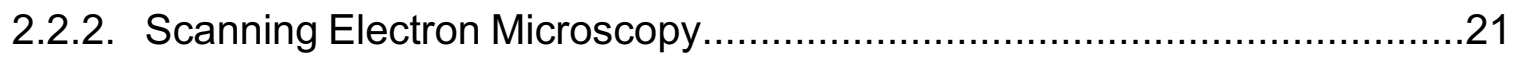

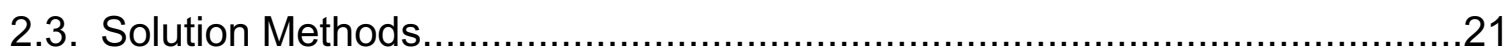

2.3.1. Determination of Deposition Potential of Ag..................................22

2.3.2. Electrodeposition of Ag Nanoneedles on Au TED..............................22

2.3.3. Electrodeposition of Ag Nanoparticle film on Au TED device....................24

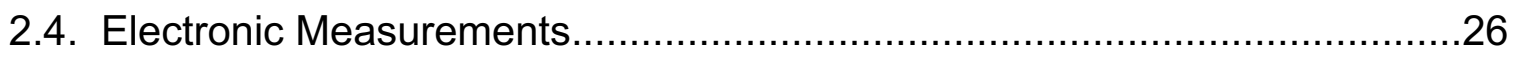

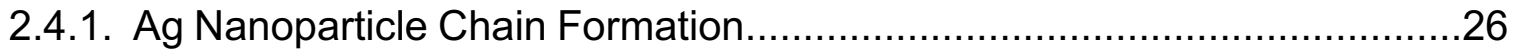

III. SYNTHESIS OF SINGLE 1D CHAINS ACROSS MICROGAP ELECTRODES

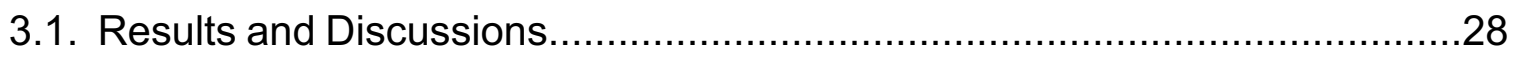

3.1.1. Results of the Ag Nanoneedle Method...........................................28

3.1.2. Ag NP Film Method for Fabrication of Single Ag Nanoparticle Chain Across

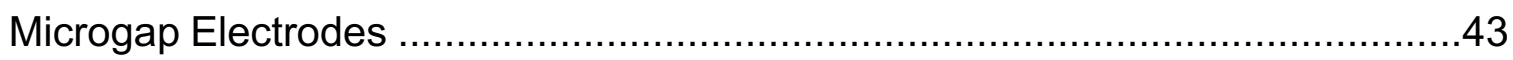

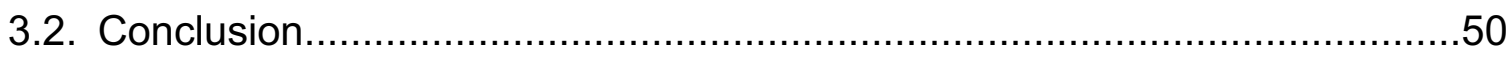

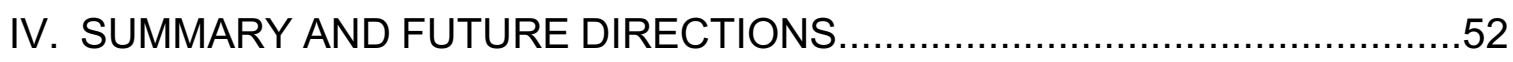

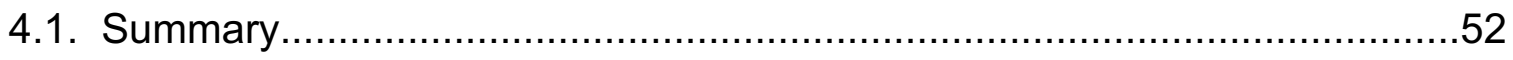

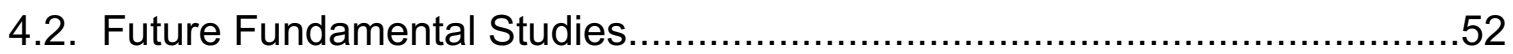

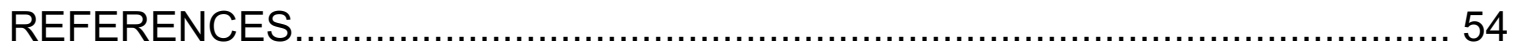

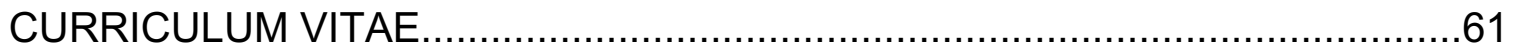




\section{LIST OF TABLES}

TABLE PAGE

1.1. Summary relation between humidity to voltage at which Ag nanoparticle chains formed. 9

3.1 Overall i-V data and SEM image results of different TEDs with single 1D Nano chains synthesized using Ag needle deposition 39

3.2. Electronic properties and SEM images of the various 1D Ag NP chains using Ag NP deposition method. 49 


\section{LIST OF FIGURES}

FIGURE

PAGE

1.1. Different types of nanoparticle assemblies .5

1.2. A) Current time plot of the Ag NP deposited IDA device at $5 \mathrm{~V}$. B) SEM image of the whole IDA device with multiple chains. C, D) Zoomed in SEM images of the 1D NP chains 10

2.1. SEM image of the bare two electrode device (TED). 14

2.2. Various steps involved in cleaning and wiring of the electrode devices.......16

2.3. Cyclic voltammogram of an Au TED in $1 \mathrm{M} \mathrm{H}_{2} \mathrm{SO}_{4}$

2.4. Image showing three electrode set-up used for the cyclic voltammetry and chronocoulometric deposition of Ag. 19

2.5. Image showing the two-electrode setup used in the pico amp booster of $\mathrm{CHI}$ 660A. Inset shows the attachment of the reference electrode (white clip) and counter electrode (red clip) to one lead of the device and working electrode (green) to the other lead. This allows the measurement of a two electrode $\mathrm{i}-\mathrm{V}$ curve in air. .20

2.6. (A) Cyclic Voltammogram of $5 \mathrm{mM} \mathrm{AgNO}_{3}$ in $0.1 \mathrm{M} \mathrm{H}_{2} \mathrm{SO}_{4}$. (B) Chronocoulometric plot for the deposition of $\mathrm{Ag}$ nano needles using $5 \mathrm{mM} \mathrm{AgNO}_{3}$ in $0.1 \mathrm{M} \mathrm{H}_{2} \mathrm{SO}_{4}$. Inset showing the SEM images of nanoneedles on the $\mathrm{Au}$ TED. 
2.7. Ag deposition on $\mathrm{Au}$ TED using $10 \mathrm{mM} \mathrm{AgNO}_{3}$ in water by

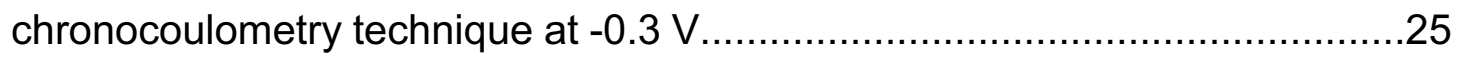

2.8. Overall process of synthesizing chains across the microgap $\mathrm{Au}$ electrodes.

3.1. (A) i-V curves of the TED device before (black) and after (red) deposition of Ag nano needles by passing $5 \times 10^{-5} \mathrm{C}$ of charge in 4 seconds, causing the Ag to cross the electrode gap and make a connection as shown in the SEM image in C. (B) i-V curve of TED before (black) and after (red) deposition of Ag nano needles on both sides by passing $1.7 \times 10^{-5} \mathrm{C}$ of charge in 1.5 seconds where the Ag nano needles did not cross the gap. 30

3.2. A) Current-time plot corresponding to the bare TED device at $10 \mathrm{~V}$. B) SEM of the bare TED with no chains. C) Current- time plot showing the current spikes when $5 \mathrm{~V}$ was applied across the TED D) SEM image of TED Device after Ag deposition, CTAB treatment and application of $5 \mathrm{~V}$ for 450 seconds. Multiple $\mathrm{Ag}$ nanochains were formed across the gap corresponding to the jumps in the current time plot $(\mathrm{C})$

3.3. A) Current-time plot of the Ag needle deposited TED with no current spikes when $1 \mathrm{~V}$ was applied B) Small current spike (shown by arrow) followed by the $10^{-3} \mathrm{~A}$ spike at 257 seconds at 2 V. C) Zoomed in image of the small spike (shown by arrow in image $A$ ) which is at the $10^{-4} \mathrm{~A}$ level. D) i-V curve of TED after chain formation (E, F) SEM images of the TED. (E) Zoomed in image of the single 1D Ag connection 33

3.4. A) Current-time plot of $\mathrm{Ag}$ nanoneedle TED at $1 \mathrm{~V}$ with no current spikes. B) Current-time plot showing a current spike at 620 seconds with a magnitude of $8 \times 10^{-5} \mathrm{~A}$ when $2 \mathrm{~V}$ was applied across the electrode. $\mathrm{C}$ ) $\mathrm{i}-\mathrm{V}$ plot showing 
the current flowing through the device after i-t plots. D, E) SEM images of TED device with single 1D Ag nanoparticle chains. Black circle shows the apparent shortest electrode gap in image $\mathrm{D}$, but no chain formed there.

3.5. $(\mathrm{A}, \mathrm{B}) \mathrm{i}-\mathrm{T}$ plots of TED at $1 \mathrm{~V}$ and $2 \mathrm{~V}$ where no spikes were observed when $1 \mathrm{~V}$ was applied and $4 \times 10^{-6} \mathrm{~A}$ current spikes were observed when $2 \mathrm{~V}$ was applied. C) i-t plot after going back to $1 \mathrm{~V}$ D) i-V plot showing the final current flow through the TED after chain formation. (E, F) SEM images of the TED after chain formation.

3.6. (A, B) i-t plots of TED at $1 \mathrm{~V}, 2 \mathrm{~V}$ and $1 \mathrm{~V}$ where no spikes were observed when $1 \mathrm{~V}$ was applied, $1.4 \times 10^{-4} \mathrm{~A}$ current spikes were observed when $2 \mathrm{~V}$ was applied, which then increased to $6 \times 10^{-3} \mathrm{~A}$ when $1 \mathrm{~V}$ was applied again. D) i-V plot showing the current flow in the TED after chain formation. (E, F) SEM images of the single Ag nanowire type connection across the TED. 38

3.7. $A, B$ ) Current time plots while applying $3 \mathrm{~V}$ and $1 \mathrm{~V}$, where there was a big spike of $9 \times 10^{-4}$ A current followed by several smaller spikes of $10^{-5} \mathrm{~A}$. C) SEM image of the device having one prominent chain and several smaller side chains connecting the nanoneedles on the electrodes 41

3.8. A) Completely fused Ag nanoneedles during the deposition process 42

3.9. $A, B)$ Current time plot of a Ag NP film device soaked in CTAB for 3 hours at $1 \mathrm{~V}$ and $2 \mathrm{~V}$. (C) i-V plot of the TED after chain formation. D,E) SEM images of the device after the current time and i-V plot. Showing a chain connecting the electrodes that are broad at the positive and thin at the negative electrode. 44

3.10. (A, B) i-t plot of a Ag NP film device showing no spikes when $1 \mathrm{~V}$ was applied and multiple current spikes when $2 \mathrm{~V}$ was applied over a period of time. 
(C, D and E) Corresponding SEM images showing multiple 1D chains across the microgap. The arrows and numbers in Figure $B$ correlate with the 5 connections observed in the SEM images.

3.11. (A, B) Current time plots of the device with A) no current spike at $1 \mathrm{~V}$ and B) Single current spike of magnitude $10^{-5} \mathrm{~A}$ at a potential of $2 \mathrm{~V} \mathrm{C}$ ) The current increased to $10^{-4} \mathrm{~A}$ when a potential of $1 \mathrm{~V}$ was applied. D) i-V plot showing the final current flowing through the device. E) SEM image of the whole device with a single Ag NP connection. F) Zoomed in view of the Ag NP chain 47

3.12. Current time plots of the device with A) no current spike when $1 \mathrm{~V}$ was applied. B) Single current spike at $350 \mathrm{~s}$ of $10^{-4} \mathrm{~A}$ at a potential $2 \mathrm{~V}$ C) Current spike increased to $10^{-3} \mathrm{~A}$ when $1 \mathrm{~V}$ was again applied. D) $\mathrm{i}-\mathrm{V}$ plot showing the final current flowing through the device. E) SEM image of the gap area showing a single connection. F) Zoomed in view of the Ag NP chain 48 


\section{CHAPTER I}

\section{INTRODUCTION}

\subsection{Main Goal}

The main goal of this study was to develop a procedure to synthesize a single one-dimensional (1D), metal nanoparticle chain (particularly Ag nanochain) across a $5 \mu \mathrm{m}$ electrode gap of a two-electrode device (TED) with high reproducibility and control over the morphology and electronic properties. The single 1D Nano chains have been synthesized by an electrochemical method reported by Shah and Zamborini, ${ }^{1}$ but with modifications in order to better control the chain formation process.

This dissertation has been divided into 4 chapters. Chapter 1 highlights the fundamental concepts, background and importance of 1D nanochains. It also describes previous work in our group that produced multiple chains and describes the mechanism behind the process. Chapter 2 describes the device fabrication and electrochemical procedures used in the nano chain synthesis. Chapter 3 shows the results of the single 1D Ag nanoparticle chain experiments, mainly through electrochemical measurements, conductivity and scanning electron microscopy (SEM) images. Chapter 4 summarizes the thesis with conclusions, future directions and potential applications of this research.

\subsection{Motivation and Objective}

Our group previously worked on the synthesis of 1D Ag NP chains across the electrode microgaps using a simple electrochemical method which usually resulted in the formation of multiple chains across the microgap electrodes. 
The problem was with the lack of reproducibility in the number of chains formed and the electronic properties which motivated us to develop a method to form just one single 1D nanoparticle chain across the microelectrode gap. It is important to form single Ag NP chain which are well defined for nanoelectronic and sensing device applications. Our objective was to synthesize controlled and reproducible 1D NP chains for resistive switching and sensor applications.

\subsection{Nanostructures and their Importance}

There is tremondous interest in metal NPs due to their unique, physicochemical properties and surface plasmon behavior. ${ }^{2-4}$ Applications of these nanostructures include catalysis, ${ }^{5-6}$ imaging, ${ }^{6}$ therapy, ${ }^{7}$ surfaceenhanced raman scattering (SERS), ${ }^{8}$ local surface plasmon resonance $(\mathrm{LSPR})^{9}$ and surface enhanced fluorescence(SEF). ${ }^{10-11}$ These metal nanoparticles are synthesized first and then assembled to form nanoassemblies. Controlled assembly on surfaces is often required to maximize their use in several applications.

\subsection{Synthesis of Metal Nanoparticles}

The synthesis of metal NPs has been intensely studied for over the past 20 years. The reduction of metal salt precursors $\left(\mathrm{M}^{\mathrm{n}+}\right)$ to $\mathrm{M}^{0}$ in the presence of stabilizers results in the formation of NPs of controlled size and shape. ${ }^{12}$ Different methods have been developed for the synthesis of metal NPs, such as like the polyol method, seed mediated synthesis and electrochemical method.

The Polyol synthesis involves the reduction of the inorganic metal precursor in the presence of alcohol molecules with multiple hydroxyl groups, 
such as $\mathrm{PVP}^{13}$ at elevated temperatures. $\mathrm{AgNO}_{3}$ in presence of ethylene glycol (EG) and PVP (poly (vinyl pyrrolidone)) resulted in the formation of different shapes of silver nanostructures depending on the temperature of the reaction. ${ }^{14}$ The polyol synthesis has been developed to synthesize different metal NPs such as $\mathrm{Ag},{ }^{15-16} \mathrm{Pt},{ }^{17-19} \mathrm{Au},{ }^{16,}$ 20-21 and $\mathrm{Cu}^{22-23}$

Seed-mediated synthesis is another approach to synthesize metal nanoparticles, where tiny nanocrystals act as the seeds for further growth into larger nanoparticles of controlled size and shape. Small Au seeds were found grow into large spherical Au NPs when $\mathrm{AuCl}_{4}{ }^{-}$was reduced in presence of the nano seeds by Murphy and coworkers. ${ }^{24}$ This process has an advantage of controlling the size and shape by controlling the concentration of seed used for the growth and other parameters. ${ }^{15,25-26}$

The electrochemical synthesis of nano-sized transition metal particles in the presence of tetraalkylammonium salts as a stabilizer was first reported by Reetz and coworkers. ${ }^{27}$ Similarly, a high yield of suspended gold nanorods were electrochemically synthesized by using a gold metal plate as the anode and platinum plate as the cathode immersed in an electrolytic solution containing cetyl trimethyl ammonium bromide (CTAB) which acts as a supporting electrolyte and stabilizer, preventing further growth of Au NP size. 28 Our group reported an electrodeposition method for the synthesis of 1D structures $^{29-30}$ and later $\mathrm{Ag}$ nanoparticles ${ }^{1}$ were electrodeposited on interdigitated array electrodes for Ag NP chain formation at the microgap electrodes. 


\subsection{Assembly of Metal Nanoparticles into 1D Chains}

Metal nanoparticles can be thought of a building blocks for the construction of advance tunable materials, which are classified into different groups based on the assemblies formed These assemblies are categorized into one dimensional (1D), two dimensional (2D) and three-dimensional systems (3D) (Figure1.1). 1D assemblies seem to have attracted the most attention mainly due to the fascinating optical properties, ${ }^{31-34}$ and sensing properties of their assemblies. ${ }^{29-30,35}$ There are many structures in the literature assemblies describing 1D metal NP assemblies.

\subsubsection{D Metal NP Assembly by Lithography}

$\mathrm{Au}$ NPs have been deposited onto predefined positions on a silica surface using an AFM tip inked with NPs in a solvent medium, which on evaporation of solvent resulted in NP chain structures. ${ }^{36}$ This technique was then developed into a Dip-Pen Nanolithography technique where precise 1D Au NP chain were fabricated. ${ }^{37}$ Plasmonic NP structures have been synthesized by mechanical scratching of PMMA-Au NPs on a substrate by AFM Lithography. ${ }^{38}$ The direct arrangement of NPs on a substrate was also achieved by nanoimprint lithography ${ }^{39}$ and scanning probe lithography. ${ }^{40}$

Lithography techniques also include top down approaches, such as electron beam lithography where a bulk material is sculpted into 1D NP chains. ${ }^{41}$ These techniques need high energy exposure and extra etching steps which requires expensive apparatus and is not industrially scalable.

\subsubsection{Template-Directed Assembly of 1D Metal NPs}

Metal NPs could be arranged with the help of a template which is known as template directed assembly. Templates that direct the NPs into assembles 


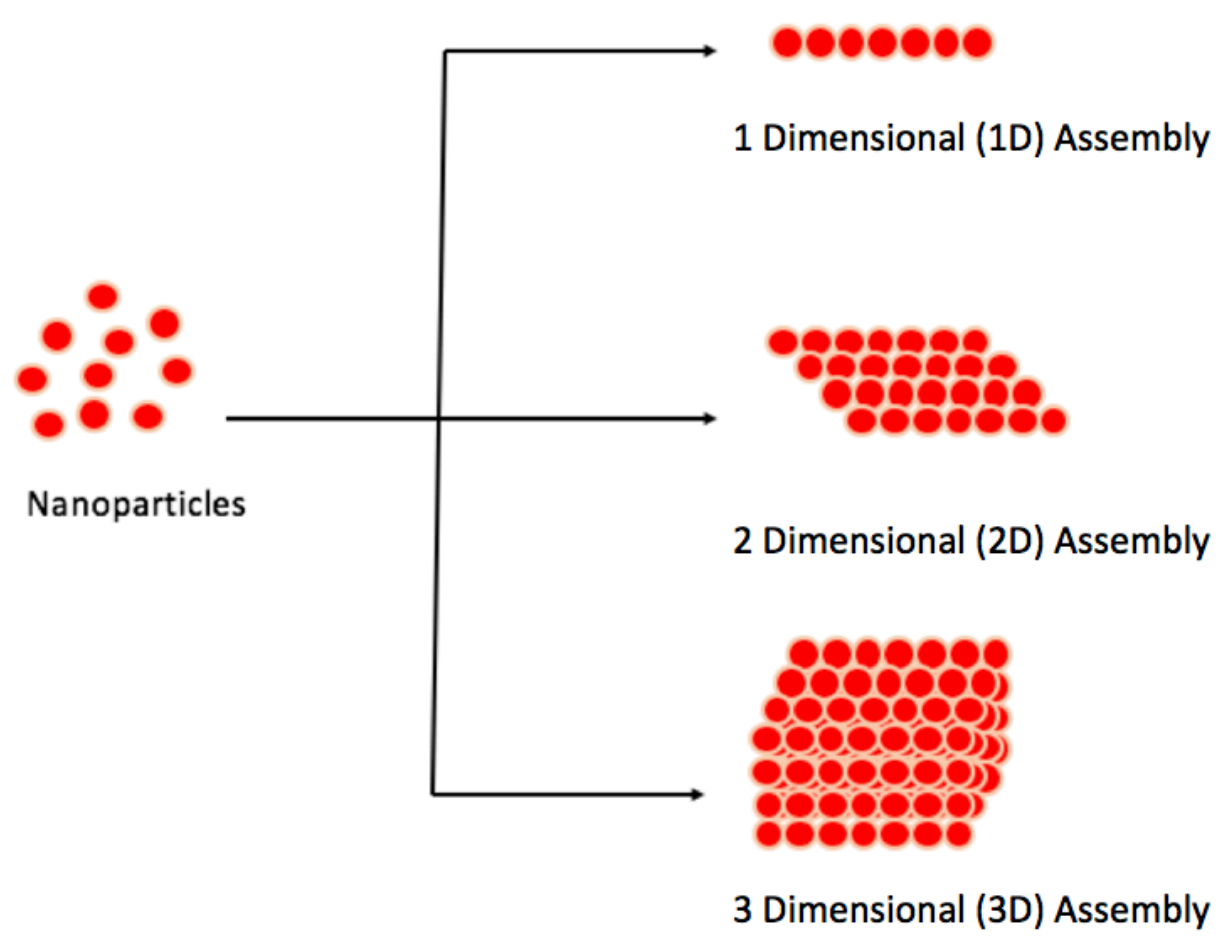

Figure.1.1. Different types of nanoparticle assemblies. 
are sub-divided into two classes soft and hard templates, depending on the template structure.

\section{Soft templates}

Soft templates are molecules or materials that are non-rigid, such as DNA, biomolecules and peptide fibrils. The development of 1D nanochain of metal NPs with DNA as a template was first reported by Schultz et al. were they attached individual metal NPs to a DNA oligonucleotide, upon addition of a complementary single stranded DNA, 1D NP chain formed. ${ }^{42}$ From then, DNA has been used for building various 1D plasmonic structures. ${ }^{43-46}$

Apart from DNA, biomolecules such as amyloid fibrils ${ }^{47}$ and peptides have been used for 1D assemblies. ${ }^{48}$ Interestingly, viruses have also been similarly used as templates in the synthesis of 1D NP chains. ${ }^{49}$

\section{Hard Templates}

Hard templates are rigid structures which act as templates. Various sol gel methods have been used to fill CNTs with various metals and subsequent heating led to the synthesis of Au NP chains upto 10 microns long. ${ }^{50}$ Similarly, different 1D Cu, ${ }^{51} \mathrm{Pt}^{52-53}$ and $\mathrm{Pd}^{54}$ nanostructures have been synthesized using CNT's as templates. Sangeeta et, al. had electrodeposited Ag NPs onto carbon nanotubes. These carbon nanotubes filled with $\mathrm{Ag}$ were processed to obtain 1D nanochains. ${ }^{35}$

\subsubsection{Chemical Assembly of 1D Metal NP Chains}

There are several methods for assembling metal NPs chemically into 1D structures. The mechanism of 1D assembly varies depending on the specific approach. For example, Au NPs aggregated into linear assemblies in the presence of 2-naphthalenethiol due to the charge repulsion potential of the 
nanospheres. ${ }^{55}$ Also, $\mathrm{Au}$ NPs were found to form $1 \mathrm{D}$ aggregates in a salt solution in the presence of ethanol due to a dipole effect. ${ }^{56}$ It was also reported that citrate coated Au NPs self-assembled into 1D chains in the presence of thiourea due to the Vorman-like effect, where a surface polarity is induced on to the $\mathrm{Au}$ NPs due to the displacement of the negatively charged citrate molecules by thiourea. ${ }^{57} 1 \mathrm{D}$ self-assemblies have also been synthesized using bi-functional slinker molecules through covalent attachment ${ }^{58}$ and hydrogen bonding. ${ }^{59-60}$ Other template free 1D nano assemblies include assembly due to magnetic force ${ }^{61}$ or due to electric fields. ${ }^{62-65}$

\subsection{Assembly of Metal Nanoparticles between Electrode Gaps.}

The assembly of metal NPs between electrode gaps has been of high interest due to various potential applications, such as sensing, ${ }^{29,} 35$ plasmonics $^{66-67}$ and nanoelectronics. ${ }^{66,68-69}$ Dielectrophoresis is popular technique used to assemble metal NPs across the electrode microgaps. A nonuniform AC or DC electric field creates dipoles in the Au NPs which leads to the formation of 1D nanostructures between the electrode gaps. ${ }^{70}$ Similar assemblies of $\mathrm{Ag}$ and $\mathrm{Pd}$ have been also been produced. ${ }^{71}$ This technique is known as Dielectrophoresis (DEP) and is used widely to assemble NPs between microgap electrodes. ${ }^{62,}$ 69-73 Aside from this technique, electrochemical methods can also be used for the assembly of 1D metal NPs between electrodes. ${ }^{69}$

Our group recently reported on the template free electrochemical synthesis of 1D metal nanostructures between electrode microgaps. Dasari et al., synthesized 1D Ag NWs across the interdigitated array electrodes (IDA) separated by a $5 \mu \mathrm{m}$ gap. ${ }^{29}$ This was very simple as the deposition of Ag led 
to the growth of the nanowire from one electrode to the other electrode, forming a connection. Later, Shah and Zamborini developed an electrochemical technique for the formation of 1D Ag NP chains in air. The oxidation of $\mathrm{Ag}$ at the positive electrode and redeposition of $\mathrm{Ag}^{+}$ions at the negative electrode occurred in air, where a surfactant CTAB was found to act as a supporting electrolyte and humid environment completed the electrochemical cell. ${ }^{1}$ It was found that in the absence of humidity the Ag NP chains were not formed even when $10 \mathrm{~V}$ was applied for 1000 seconds. The experiment was carried out under different levels of humidity from $20 \%$ to $50 \%$. At $20 \%$ humidity, no chains were formed across the electrode at $10 \mathrm{~V}$. As the humidity level increased to $25 \%$, chains started to form at $10 \mathrm{~V}$. As the percentage of humidity increased the potential required to form the chains decreased (Table 1.1).

Similar studies were performed without CTAB, where there was no formation of chains in the absence of CTAB. After drop cast deposition of a drop of $1 \times 10^{-5} \mathrm{M}$ CTAB, Ag nanochains were readily formed across the electrode gap. These studies helped in understanding the formation mechanism of Ag nanochains but did not achieve single 1D NP chains across the electrodes. When $5 \mathrm{~V}$ was applied across the $\mathrm{Ag}$ deposited IDA current spikes appeared in the current - time plot (Figure 1.2.A) and the corresponding SEM image (Figure 1.2 B, C and D) showed multiple 1D Ag nanochains across the electrodes. The work in this thesis is similar, but more focused on the controlled synthesis of one single nanochain across the two-electrode device (TED). 
Table1.1 Summary relation between humidity to voltage at which chains formed.

\begin{tabular}{|c|c|}
\hline Relative Humidity & Voltage required to form chains \\
\hline $20 \%$ & $\begin{array}{c}\text { No chain formed upto } 10 \mathrm{~V} \text { for } \\
1000 \mathrm{~s}\end{array}$ \\
\hline $25 \%$ & $10 \mathrm{~V}$ \\
\hline $30 \%$ & $10 \mathrm{~V}$ \\
\hline $35 \%$ & $6 \mathrm{~V}$ \\
\hline $40 \%$ & $5 \mathrm{~V}$ \\
\hline $50 \%$ & $5 \mathrm{~V}$ \\
\hline
\end{tabular}



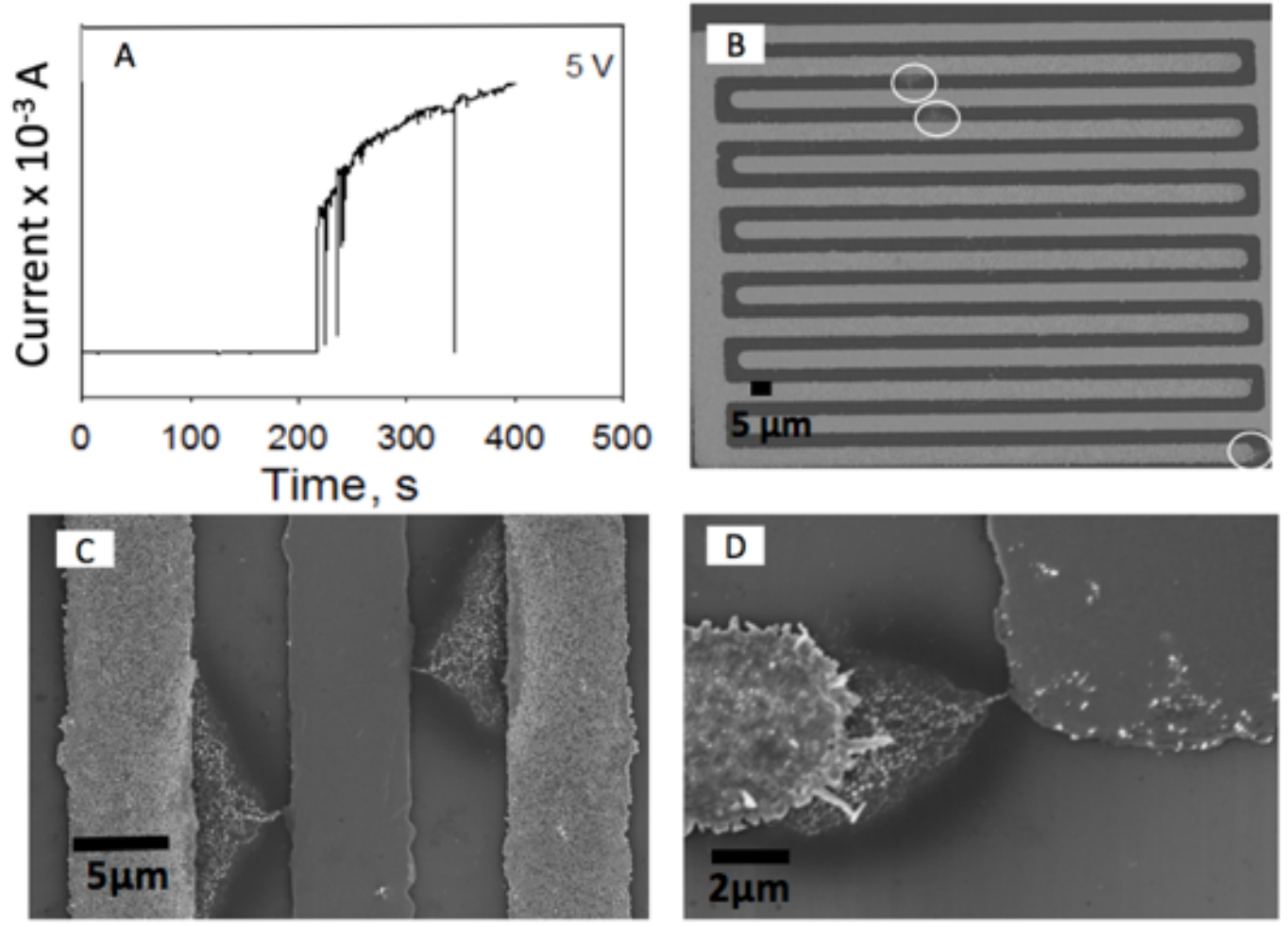

Figure 1.2 A) Current time plot of the Ag NP deposited IDA device at $5 \mathrm{~V}$. B) SEM image of the whole IDA device with multiple chains. C, D) Zoomed in SEM images of the 1D NP chains. 


\subsection{Application of 1D Nanoparticle Chains}

1D NP chains exhibit unique properties, such as interparticle photonic, electronic and energy transfer properties, which make them interesting materials for the production of next generation electronic and photonic devices. ${ }^{74-75} \mathrm{Pd}$ NP chains were found to be excellent building blocks for hydrogen gas sensing applications. ${ }^{76-78} \mathrm{Pd}$ NPs adsorb hydrogen molecules and expand when exposed to hydrogen gas increasing the resistance of the Pd NP chain. Similar sensing properties have been reported for Au NPs for sensing $\mathrm{H}_{2} \mathrm{~S}$ gas. ${ }^{79}$ Wave guiding is found to be another promising application of Ag NP chains, where dampening of plasmon propagation along NP chains ${ }^{80}$ makes them useful in the field of nearfield microscopy and data storage. ${ }^{81}$ These metallic NP chains also show localized surface plasmon resonance, which leads to enhanced absorption, reflection and efficient coloration due to the spatial coupling of the NPs. ${ }^{82-83}$

Metal NP assembly across electrode gaps may also serve in the building of data storage devices using Nonvolatile Random-Access Memory. ${ }^{84-85}$ These NP chains break and reform repeatedly which leads to resistive switching from a low resistance state (LRS) to a high resistance state (HRS) and vice versa. ${ }^{85-}$ 86 It is very important to understand the mechanism of switching, state which can possibly be achieved by combining Raman Scattering with conductivity measurements. ${ }^{87}$ Wong et al used Raman Spectroscopy to study the resistive random access memory process. ${ }^{88}$ Single 1D NP chains across a microgap are the best suited for understanding the mechanism of resistive switching. It can also give a very good SERS signal for molecules in the gap of the Ag NPs, allowing simultaneous spectroscopy and conductive data force better 
understanding of molecular electronics. SERS and resistive based sensing are also excellent potential applications for these 1D nanochain structures. Having a single nanochain in these types of structures makes it clear what type of chain is giving rise to the electronic or optical signal. 


\section{CHAPTER II \\ EXPERIMENTAL SECTION}

\subsection{Chemicals and Substrates}

\subsubsection{Chemicals}

Silver nitrate $\left(\mathrm{AgNO}_{3}\right)(99 \%)$, cetyltrimethylammonium bromide (CTAB) $(\geq 97.0 \%)$, isopropyl alcohol $(99.8 \%)$, acetone $(99.9+\%)$ and methanol were purchased from Sigma Aldrich and used as received. Ethanol (200 proof) was purchased from Decon Laboratories, Inc. Sulfuric acid was purchased from Allied Chemicals. Nanopure ultrapure water with resistivity of $18 \mathrm{M} \Omega-\mathrm{cm}$ was used for all of the aqueous solutions prepared.

\subsubsection{Aqua Regia Solution}

Aqua Regia was used to clean all of the glassware used for the experiments. It was prepared by mixing concentrated $\mathrm{HNO}_{3}$ and concentrated $\mathrm{HCl}$ in a 1:3 v:v $\left(\mathrm{HNO}_{3}: \mathrm{HCl}\right)$ ratio respectively. This corrosive and fuming liquid dissolves all metals such as $\mathrm{Au}, \mathrm{Pd}$ and $\mathrm{Ag}$ from the glassware. The glassware was filled with freshly prepared aquaregia solution for 30 minutes and then rinsed thoroughly several times with nanopure water.

\subsubsection{Microfabrication of $\mathrm{Au}$ Two Electrode Devices (TED) on $\mathrm{Si} / \mathrm{SiO}_{2}$}

Two electrode devices (TED) made of Au with a $5 \mu \mathrm{m}$ gap were used for most of our studies. The devices were fabricated in the clean room at the Micro Nano Technology Center at the University of Louisville. The microfabrication included photolithography, sputtering and lift off processes. In addition to the 


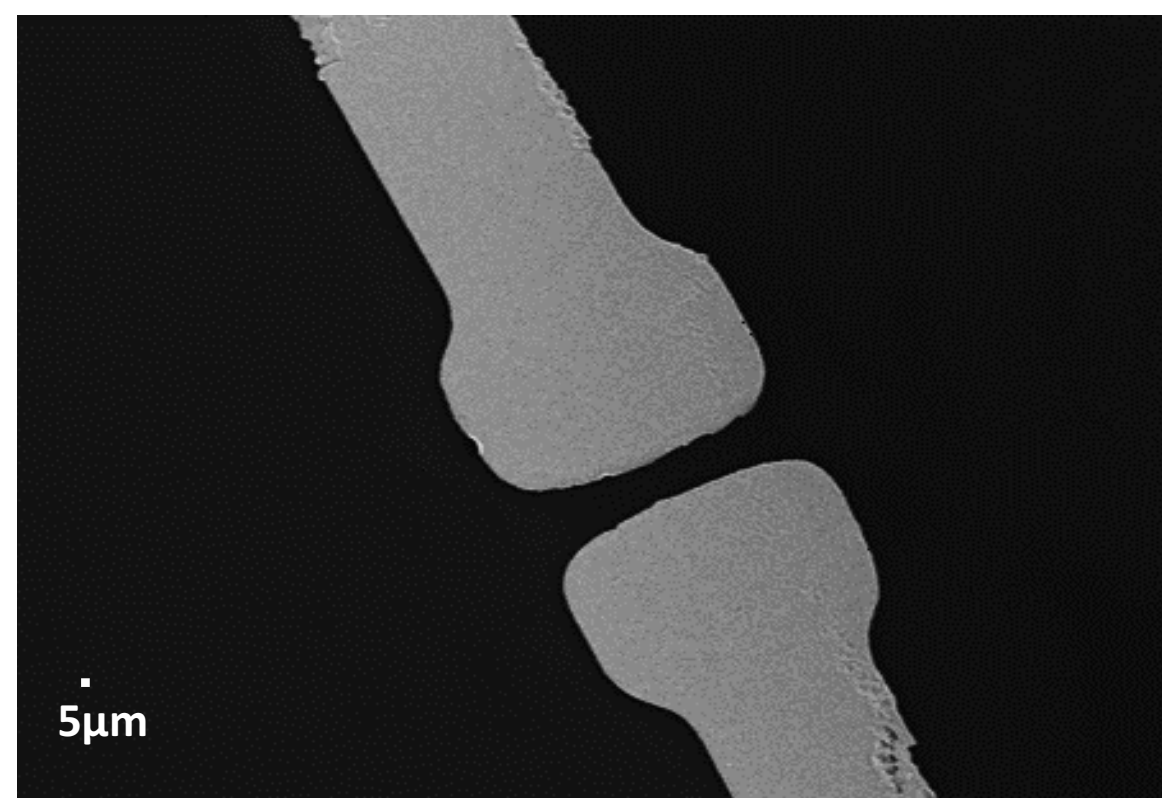

Figure 2.1 SEM image of the bare two electrode device(TED). 
TED, interdigitated array (IDA) Au electrode devices also separated by $5 \mu \mathrm{m}$ was used for some experiments. Figure 2.1 shows SEM image of TED device used in this work.

\subsubsection{Cleaning and Wiring of Au TED Electrodes}

The Au TED or IDA devices were cleaned and wired for the electrochemical studies. The overall procedure is illustrated in Figure 2.2. Initially the devices were cleaned by sonicating for 20 minutes in acetone, methanol, ethanol, water and isopropyl alcohol, followed by drying under nitrogen. Then the devices were wired using silver paint and cured in an oven at $80{ }^{\circ} \mathrm{C}$ for 4 hours. The silver paint was then insulated with torr seal epoxy and cured in an oven at $80^{\circ} \mathrm{C}$ for 12 hours. The devices were placed in an ozone cleaner for 20 minutes to get remove possible organic impurities and rinsed with acetone, methanol, ethanol, water and isopropyl alcohol before drying under nitrogen. Finally, the electrodes were electrochemically cleaned by cycling from $0 \mathrm{~V}$ to $1.5 \mathrm{~V}$ in $1 \mathrm{M} \mathrm{H}_{2} \mathrm{SO}_{4}$ for about 20 cycles, making sure to have well-defined oxidation and reduction peaks for the Au. Figure 2.3 shows a cyclic voltammogram with peaks at $1.4 \mathrm{~V}$ and $0.9 \mathrm{~V}$ representing the oxidation and reduction peak of $\mathrm{Au}$ TED electrodes in $1 \mathrm{M} \mathrm{H}_{2} \mathrm{SO}_{4}$.

\subsection{Techniques}

\subsubsection{Electrochemistry}

Electrochemical techniques were used to clean, deposit Ag, form the Ag NP chains, and characterize the chains. These electrochemical experiments were carried out using the $\mathrm{CHI} 660 \mathrm{~A}$ instrument purchased from $\mathrm{CH}$ Instruments, Inc. (Austin, TX). The following are the techniques used for this study 

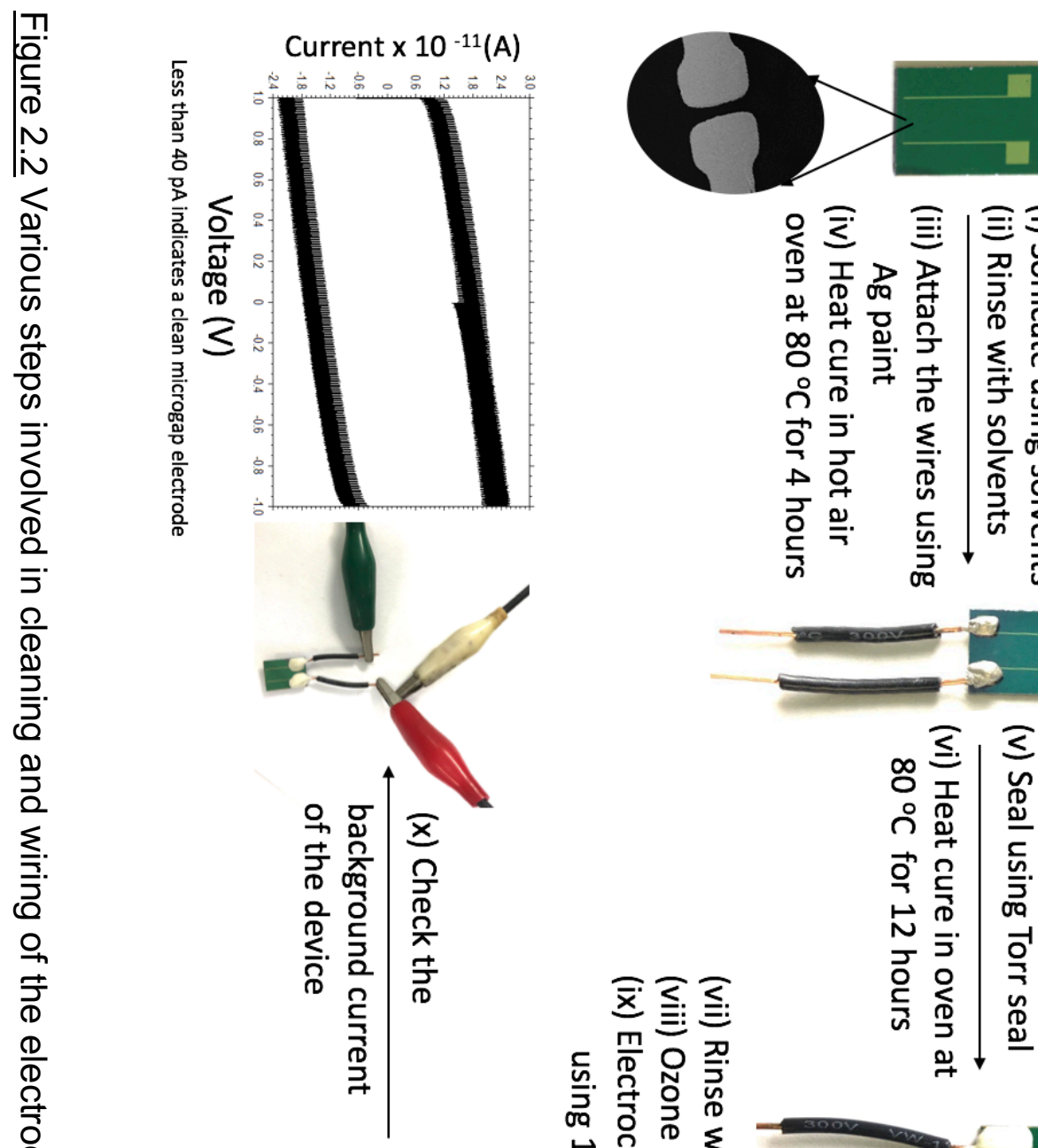

○ $\bar{\equiv} \equiv$

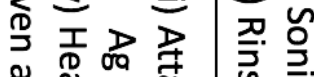

‡

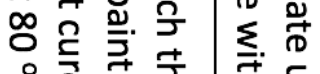

กำ 亭 声

号志 它党.
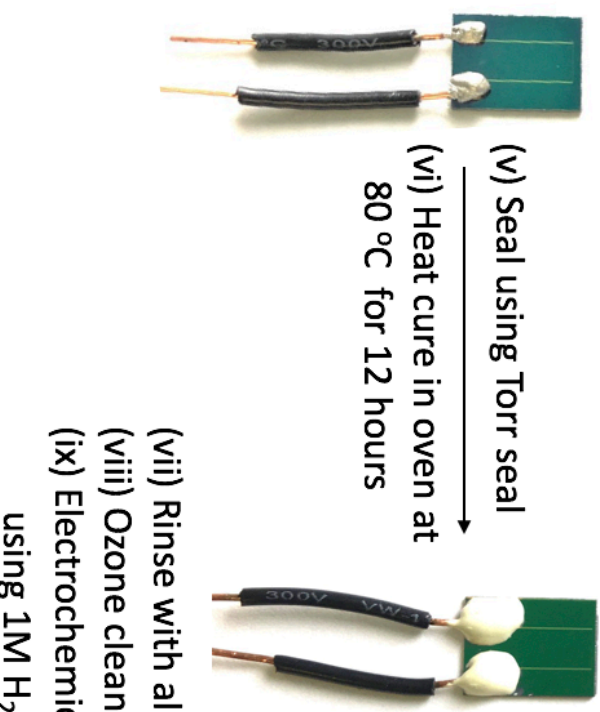

市.

Current $\times 10^{-6}(\mathrm{~A})$

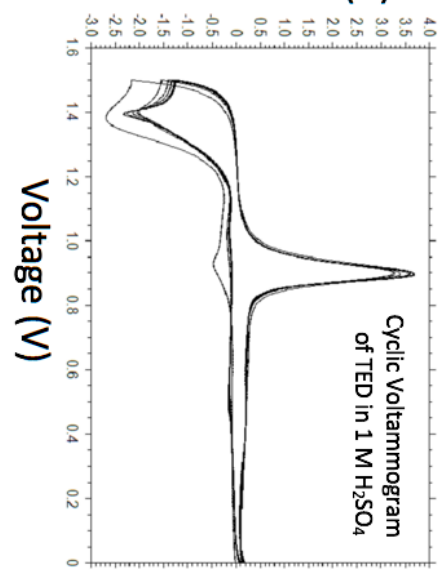

농. 을.

กำ

웡 웅

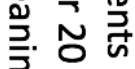

范.

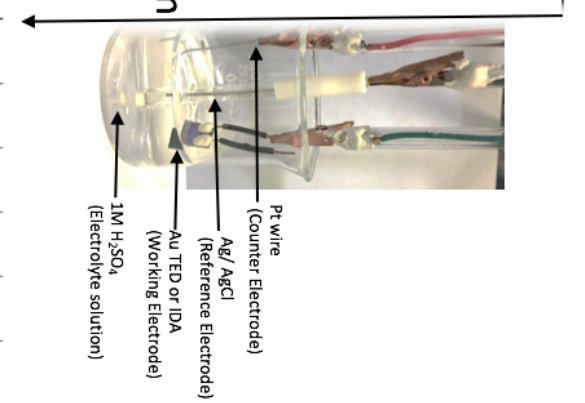




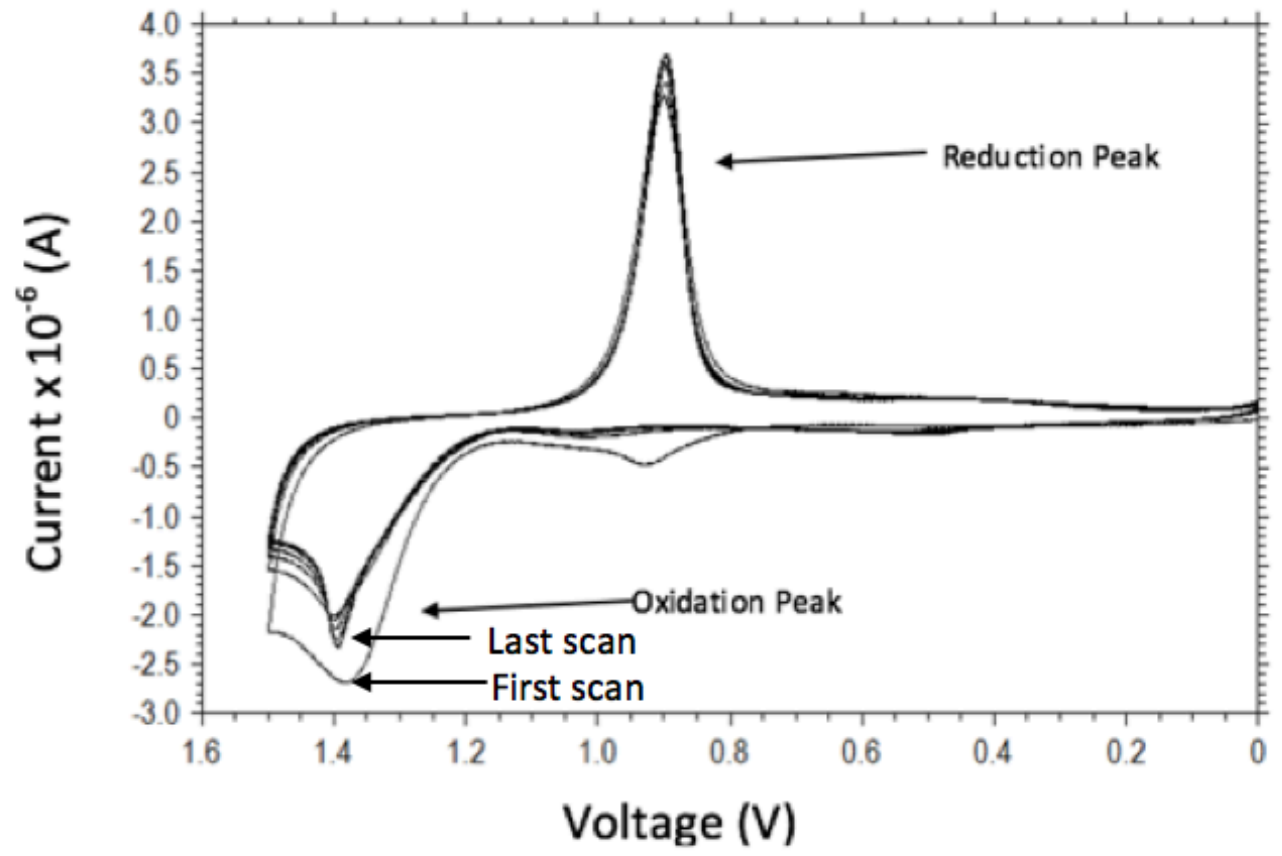

Figure 2.3 Cyclic voltammogram of an Au TED in $1 \mathrm{M} \mathrm{H}_{2} \mathrm{SO}_{4}$. 
Cyclic Voltammetry (CV): CV was used to

1) Electrochemically clean the Au electrodes in $1 \mathrm{M} \mathrm{H}_{2} \mathrm{SO}_{4}$.

2) Determine the potential for electrochemical deposition of $\mathrm{Ag}$ onto $\mathrm{Au}$ electrodes in $0.005 \mathrm{M} \mathrm{AgNO}_{3}$ plus $0.1 \mathrm{M} \mathrm{H}_{2} \mathrm{SO}_{4}$.

3) Characterize Au electrodes before and after Ag deposition in air.

4) Characterize the device after the formation of Ag NP chains in air.

Figure 2.4 shows the set up for all the cyclic voltammetry experiments in solution. The experiments were performed at room temperature using $\mathrm{Ag} / \mathrm{AgCl}$ (3 $\mathrm{M} \mathrm{KCl}$ ) as the reference electrode and a platinum wire as the counter electrode. The I-V curves to characterize the Au electrodes and the NP chains were performed in a Faraday cage in air. Figure 2.5 shows the two-electrode set up in air where the reference and counter electrode leads are attached to one electrode of the TED device and the working electrode lead is attached to the other electrode of TED.

\section{Chronocoulometry}

Chronocoulometry is an electrochemical technique where the potential of the working electrode is stepped to a constant value and the number of coulombs passed at the electrode is monitored as a function of time. We used this technique for the deposition of $\mathrm{Ag}$ onto the Au electrodes where the potential of the working electrode was stepped to a negative enough value for the $\mathrm{Ag}^{+}$ ions to reduce to $\mathrm{Ag}^{0}$ on the $\mathrm{Au}$ electrode under diffusion-limited conditions. 


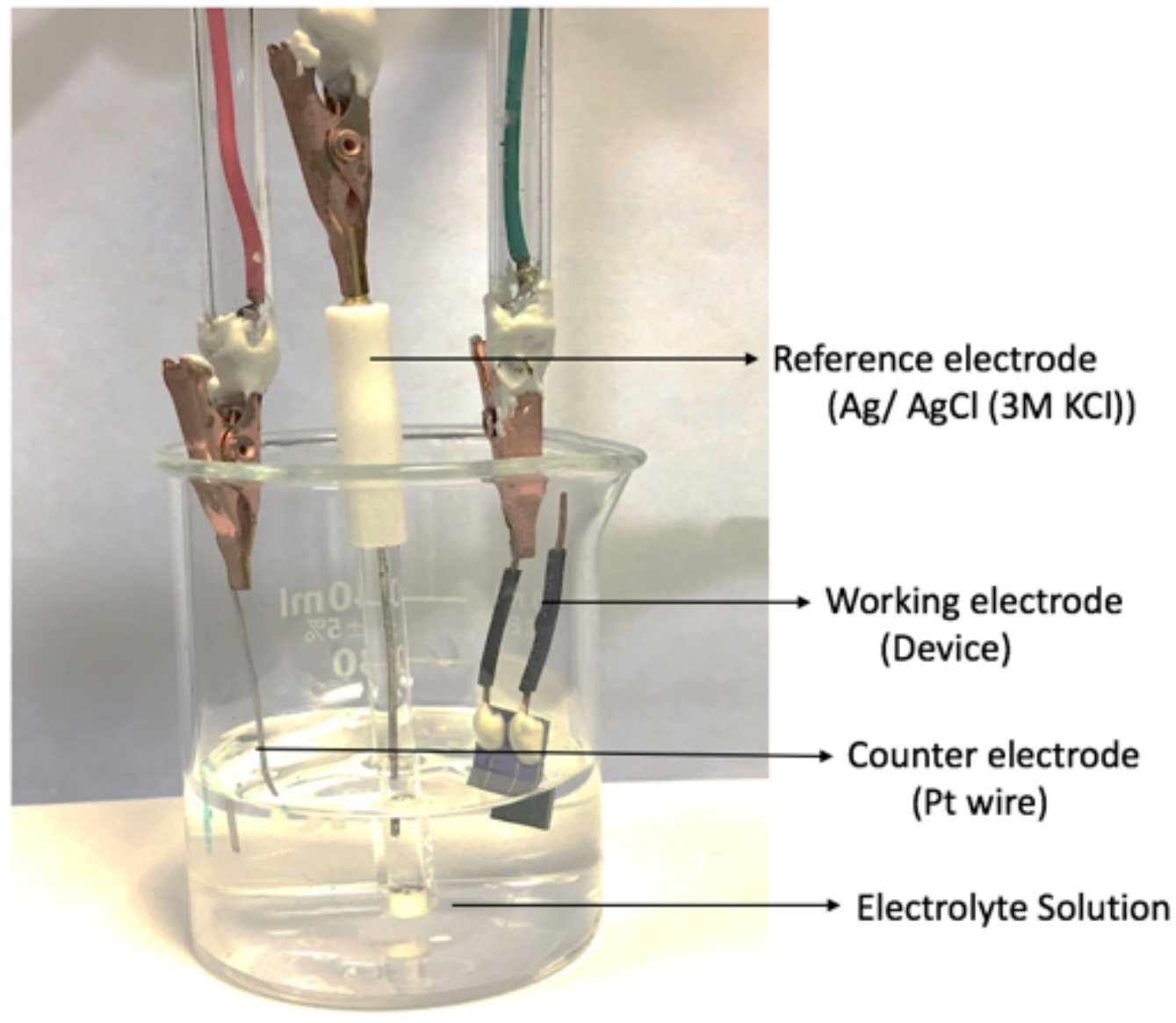

Figure 2.4 Image showing three electrode set - up used for the cyclic voltammetry and chronocoulometric deposition of $\mathrm{Ag}$. 


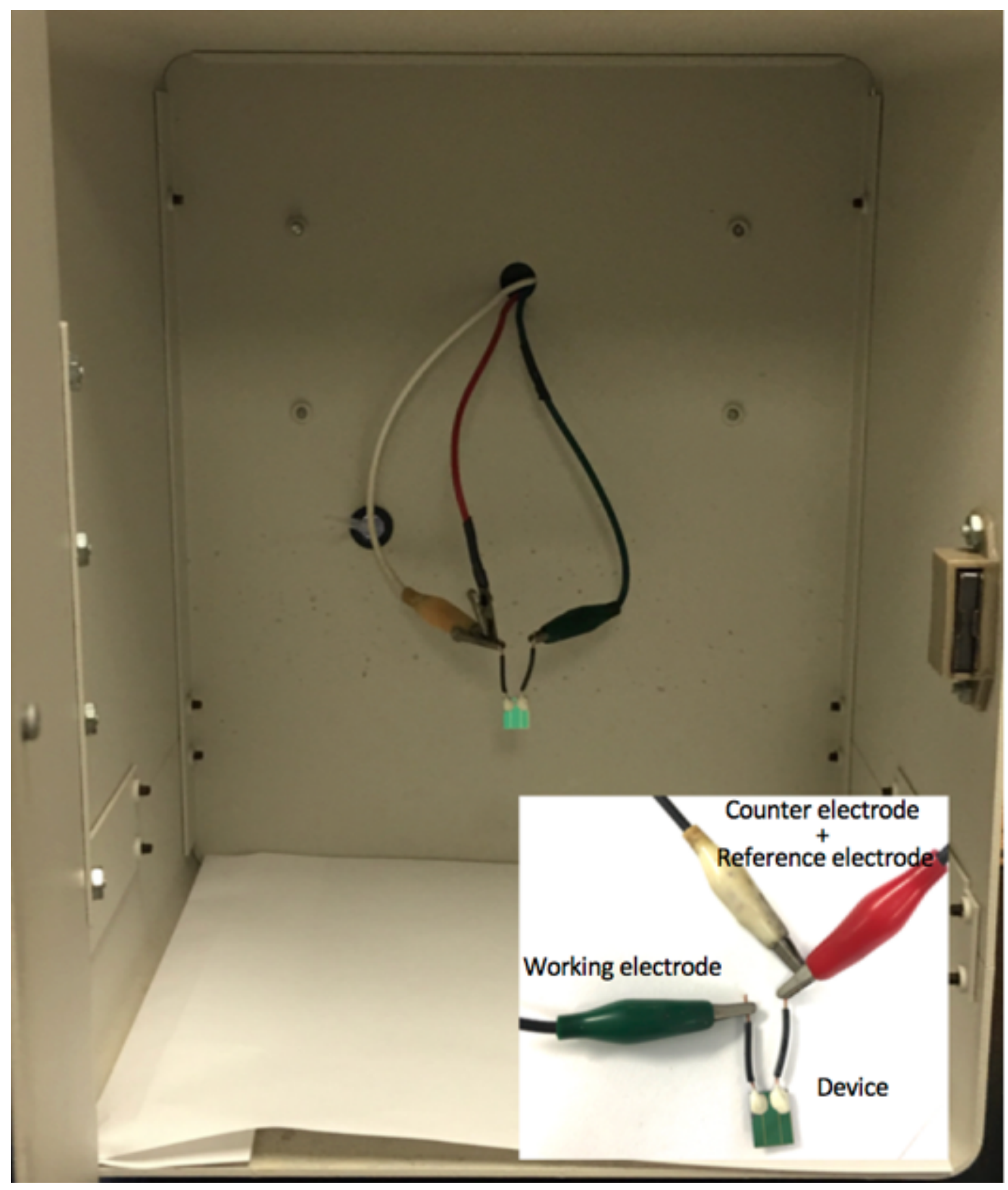

Figure 2.5 Image showing the two-electrode setup used in the pico amp booster of $\mathrm{CHI}$ 660A. Inset shows the attachment of the reference electrode (white clip) and counter electrode (red clip) to one lead of the device and working electrode (green) to the other lead. This allows the measurement of a two electrode i- $V$ curve in air. 


\section{Chronoamperometry}

Chronoamperometry is an electrochemical technique where the potential of the working electrode is stepped to a constant value and the resulting current monitored as a function of time. In our study, this technique was used to form $\mathrm{Ag}$ chains in between the microgap electrodes in air by applying a constant potential and monitoring the change in current as a function of time using the two-electrode setup. The rise in current in the current time plot indicated the formation of a connection or chain across the two electrodes.

\subsubsection{Scanning Electron Microscopy (SEM)}

SEM comes under the category of electron microscopy where the images are being produced by scanning the surface of the sample with a focused beam of electrons. A Carl Zeiss SMT AGSUPRA 35VP field emission SEM was used for all images at an accelerating voltage of $8.00 \mathrm{KV}$. The interaction between the electrons and the surface of the sample produces signals which give information on the topography of the sample surface. SEM was very helpful in this study as it provided information about the Ag NWs synthesized as well as the number and morphology of the Ag nanochains formed.

\subsection{Solution Methods}

\subsubsection{Determination of Deposition Potential of Ag}

In order to deposit Ag metal onto the electrode surface the deposition potential had to be determined. The potential was determined by obtaining a cyclic voltammogram of $\mathrm{Au}$ TED in $5 \mathrm{mM} \mathrm{AgNO}_{3}$ in aqueous $0.1 \mathrm{M} \mathrm{H}_{2} \mathrm{SO}_{4}$ by scanning from $0.6 \mathrm{~V}$ to $-0.4 \mathrm{~V}$ at a scan rate of $100 \mathrm{mV} / \mathrm{s}$ using a $\mathrm{Ag}$ wire quasi 
reference electrode and Pt wire counter electrode as in Figure 2.6 A. Silver was in the oxidized form as $\mathrm{Ag}^{+}$ions in solution. As the voltage approached near $0.0 \mathrm{~V}$ from $+0.6 \mathrm{~V}$, cathodic current started to flow due to the reduction reaction of $\mathrm{Ag}^{+}+1 \mathrm{e}^{-} \rightarrow \mathrm{Ag}^{0}$. When the direction of the potential sweep was reversed from $-0.4 \mathrm{~V}$, oxidation of $\mathrm{Ag}^{0}$ occurred near $0.0 \mathrm{Vresulting}$ in the anodic peak for the reaction $\mathrm{Ag}^{0} \rightarrow \mathrm{Ag}^{+}+1 \mathrm{e}^{-}$. The dashed line at $-0.3 \mathrm{~V}$ in Figure 2.6. $\mathrm{A}$ shows the potential used for the electrodeposition of Ag onto the Au electrodes. This is the potential determined by cyclic voltammetry and was used for the chronocoulometric deposition of $\mathrm{Ag}$ in a controlled manner.

\subsubsection{Electrodeposition of Ag Nanoneedles on Au TED}

After the TED was cleaned and checked for the background current Ag was deposited on each $\mathrm{Au}$ electrode. Ag NWs were deposited at each electrode using $5 \mathrm{mM} \mathrm{AgNO}_{3}$ in $0.1 \mathrm{M} \mathrm{H}_{2} \mathrm{SO}_{4}$ solution as the electrolyte solution using a platinum wire as the counter electrode, $\mathrm{Ag}$ wire as the quasi reference electrode, and by attaching only one lead of the TED as the working electrode to the potentiostat at a potential of $-0.3 \mathrm{~V}$. The deposition was similar to our previous work $^{30}$ but fewer coulombs was deposited in order to prevent the formation of full connection to access the gap. When $1.7 \times 10^{-5} \mathrm{C}$ of $\mathrm{Ag}$ was deposited on each electrode small dendrites (or nanoneedles) formed on both side which did not make a connection to the other side. Figure $2.6 \mathrm{~B}$ shows the chronocoulormetric plot of $\mathrm{Ag}$ deposition of $1.7 \times 10^{-5} \mathrm{C}$ at a potential of $-0.3 \mathrm{~V}$. After the deposition, the current of the TED was checked to make sure there were no connections formed between the microgap electrodes during the deposition. The TED was then used for further studies. 

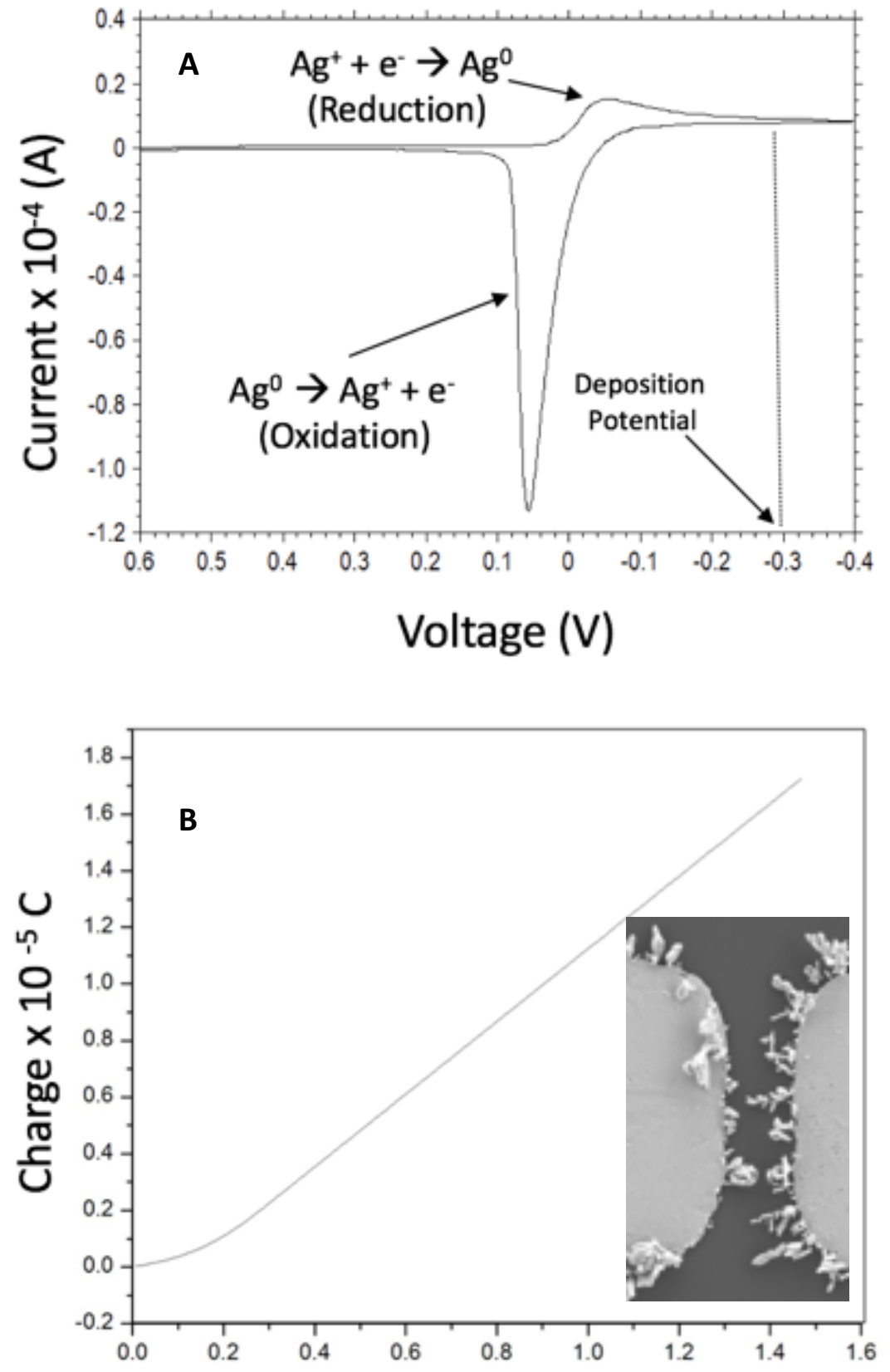

Time (s)

Figure 2.6 (A) Cyclic Voltammogram of $5 \mathrm{mM} \mathrm{AgNO}_{3}$ in $0.1 \mathrm{M}$ $\mathrm{H}_{2} \mathrm{SO}_{4}$. (B) Chronocoulometric plot for the deposition of Ag nano needles using $5 \mathrm{mM} \mathrm{AgNO}_{3}$ in $0.1 \mathrm{M} \mathrm{H}_{2} \mathrm{SO}_{4}$. Inset showing the SEM images of nanoneedles on the Au TED. 


\subsubsection{Electrodeposition of Ag NP on Au TED device}

A compact film of Ag NPs was deposited on each electrode of the TED by chronocoulometry using a solution of $10 \mathrm{mM} \mathrm{AgNO}_{3}$ in water with no other supporting electrolyte. About $6 \times 10^{-5} \mathrm{C}$ of charge was deposited on each side at $-0.3 \mathrm{~V}$, which took around 5 seconds. This deposition did not lead to the formation of any dendrites. Figure 2.7 shows the chronocoulometric plot of a TED device at $-0.3 \mathrm{~V}$ in $10 \mathrm{mM} \mathrm{AgNO}_{3}$ solution with the SEM image showing how $\mathrm{Ag}$ was deposited onto the $\mathrm{Au}$ electrodes. Deposition using $\mathrm{AgNO}_{3}$ in water was easier compared to deposition using $\mathrm{AgNO}_{3}$ in $0.1 \mathrm{M} \mathrm{H}_{2} \mathrm{SO}_{4}$ as the latter took less than 1.5 seconds for the deposition, which was much harder to monitor. Also, it would often form a connection if deposited for a few more seconds as the dendrites grew longer and touched the other electrode. This did not occur for Ag NP films. 


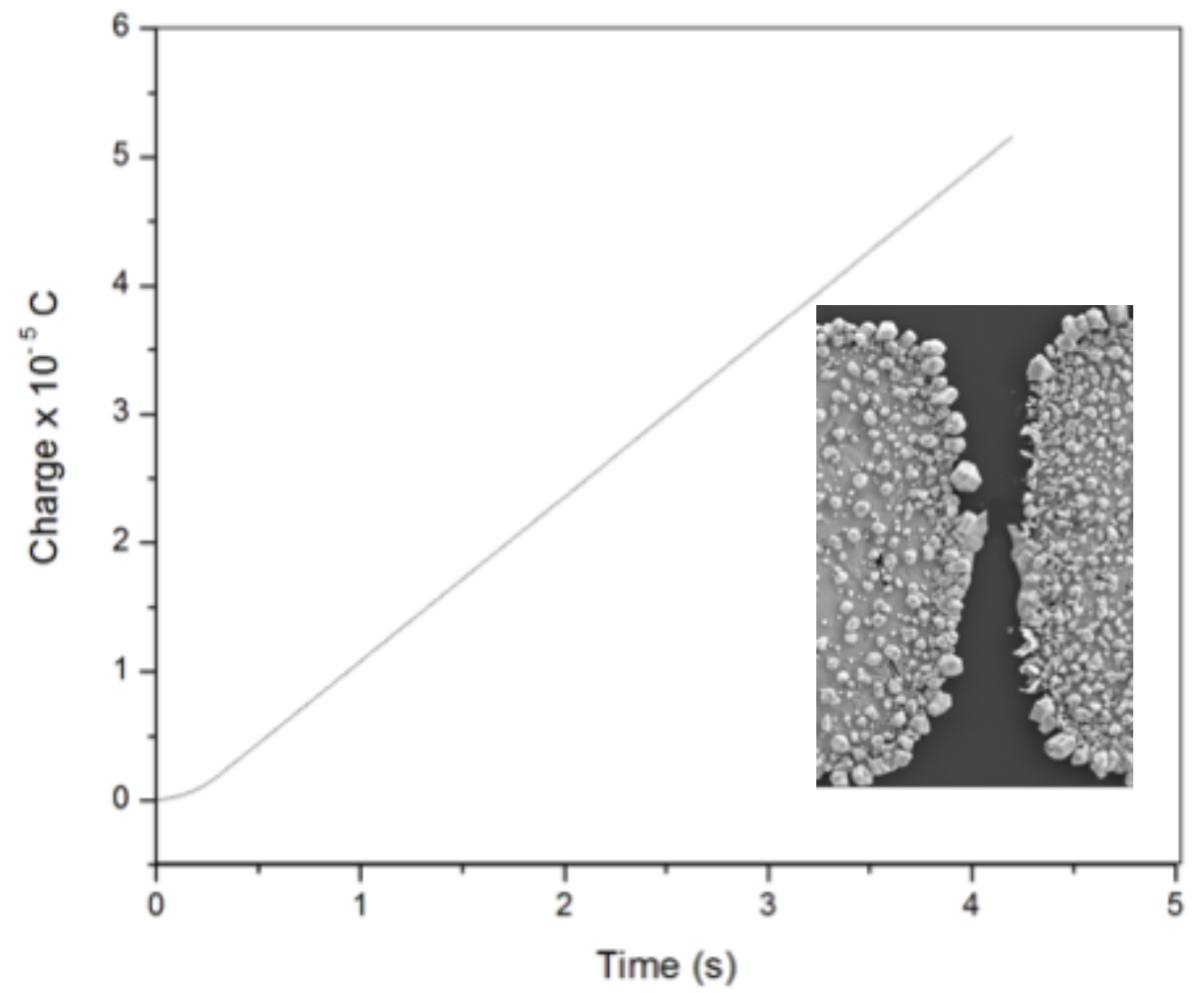

Figure $2.7 \mathrm{Ag}$ deposition on $\mathrm{Au}$ TED using $10 \mathrm{mM} \mathrm{AgNO}_{3}$ in water by chronocoulometry technique at $-0.3 \mathrm{~V}$. 


\subsection{Electronic Measurements}

\subsubsection{Ag NP Chain Formation}

The devices which did not show any connection between the electrodes after Ag deposition were used for the study of Ag NP chain formation. The absence of a connection was confirmed by running a cyclic voltammogram from $+1 \mathrm{~V}$ to $-1 \mathrm{~V}$ between two terminals set up in air. If the device showed the same current level $(<40 \rho \mathrm{A})$ before and after the deposition of $\mathrm{Ag}$ it meant that there were no connections formed during the deposition. The device was then dipped into $0.1 \mathrm{M} \mathrm{CTAB}$ solution for 3 hours, rinsed with nanopure DI water and dried under nitrogen. Then a voltage was applied between the microgap electrodes. The current was measured as a function of time to determine if a 1D Ag NP chain was formed. The chains were formed by the oxidation of $\mathrm{Ag}$ at the positive electrode to form $\mathrm{Ag}^{+}$ions which get redeposited by reduction of $\mathrm{Ag}^{+}$to $\mathrm{Ag}$ at the negative electrode leading to a spike in the current-time plot. This process happens in the presence of $\mathrm{CTA}^{+}$and $\mathrm{Br}^{-}$ions and humidity, where the surfactant $C T A B$ acts as a supporting electrolyte, making a complete electrochemical cell setup as reported previously. ${ }^{1}$ Figure 2.8 shows the overall mechanism leading to fabricate ion of NP chains across the microgap Au electrodes. 


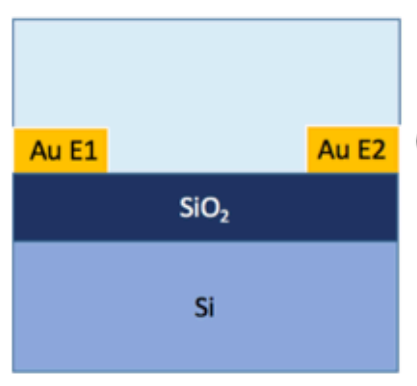

Au device after wiring and cleaning
Chronocoulometric deposition of Silver

Apply voltage

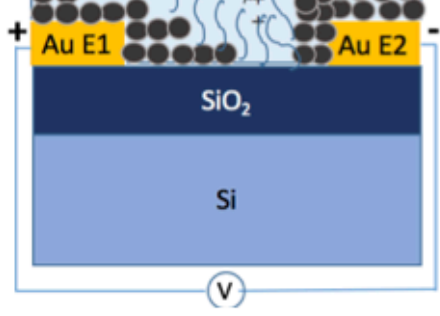

When voltage is applied,

$\mathrm{Ag}$ is Oxidized at (+) $\mathrm{E} 1\left(\mathrm{Ag}^{0} \rightarrow \mathrm{Ag}^{+}+1 \mathrm{e}^{-}\right)$

$\mathrm{Ag}^{+}$ions move towards (-) E2,

and are reduced $\left(\mathrm{Ag}^{+}+1 \mathrm{e}^{-} \rightarrow \mathrm{Ag}^{0}\right)$

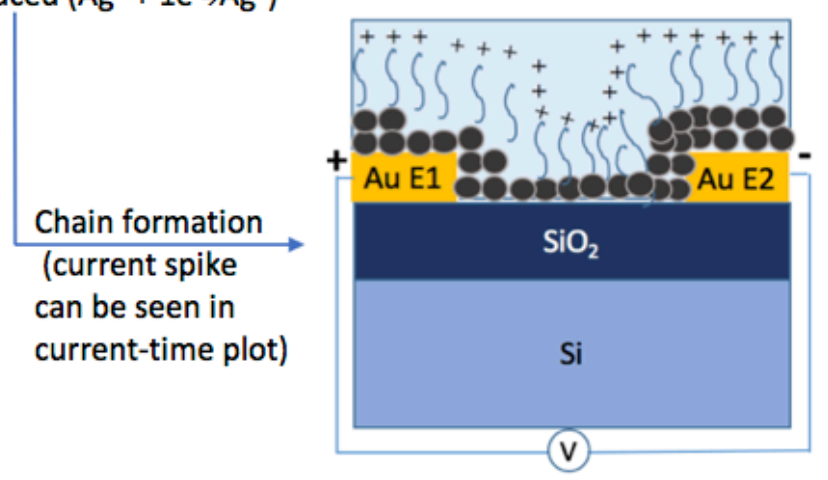

Figure 2.8. Overall process of synthesizing chains across the microgap Au electrodes. 


\section{CHAPTER III \\ FORMATION OF SINGLE 1D CHAINS ACROSS MICROGAP \\ ELECTRODES}

\subsection{Results and Discussion}

We performed two main strategies for the synthesis of single 1D Ag NP chains across an electrode microgap as described in the experimental section. The first is the Ag nanoneedle method, which involved electrodeposition of $\mathrm{Ag}$ nanoneedles onto the electrodes that did not fully cross the gap. The connection was then made by the formation of an Ag NP chain in air. The second method is the Ag NP film method, where a more uniform film of Ag NPs was electrodeposited onto each electrode. Then the gap was connected with an Ag NP chain by applying a voltage in air. The results of these two methods are described in the rest of this chapter.

\subsubsection{Results of the Ag Nanoneedle Method}

After Ag nanoneedle electrodeposition as described in the experimental section, the current flowing through the device was measured while scanning from $+1 \mathrm{~V}$ to $-1 \mathrm{~V}$ between the two electrodes in air and compared to the bare Au electrode device before $\mathrm{Ag}$ deposition to make sure that no connections formed during the deposition. The current time plot in Figure 3.1 A shows a current of $10^{-2} \mathrm{~A}$ after passing $5 \times 10^{-5} \mathrm{C}$ of charge during $\mathrm{Ag}$ nanoneedle deposition. This large current indicates that the wires have 
grown enough to touch both electrodes by crossing the microgap, which can be seen in the SEM image in Figure 3.1 C. When about $1.7 \pm 0.2 \times 10^{-5}$ Coulombs of charge passed during deposition of $\mathrm{Ag}$ nanoneedles on each electrode, the Ag nanowires grew like little protrusions at each electrode without forming any contact between the electrodes. Figure 3.1 B. shows the is- $\mathrm{V}$ curve from $+1 \vee$ to $-1 \vee$ applied between the electrodes of the bare Au device and the same device after Ag electrodeposition, revealing that there was no change in current, indicating that there was no direct $\mathrm{Ag}$ connection between the two electrodes. The SEM images of the device after deposition in Figure 3.1 D shows that the needles form at random positions on the electrodes without making a connection between them, consistent with the i-V curve. This type of device was further used for Ag NP chain formation studies.

After the electrodeposition of Ag needles, the devices were dipped in 0.1 M CTAB solution for about 3-4 hours. After soaking the device was rinsed with nanopure water for 5 seconds and dried under nitrogen. A certain voltage was applied between the two electrodes in air and the current was monitored as a function of time. Figure 3.2 A and B shows the i-t plot of a bare Au electrodes (treated with CTAB) at $10 \mathrm{~V}$ no current spikes and its corresponding SEM image. The current time plot did not show any spikes and showed flat current when a large voltage was applied between the CTAB-treated Au electrodes with no Ag deposition. 

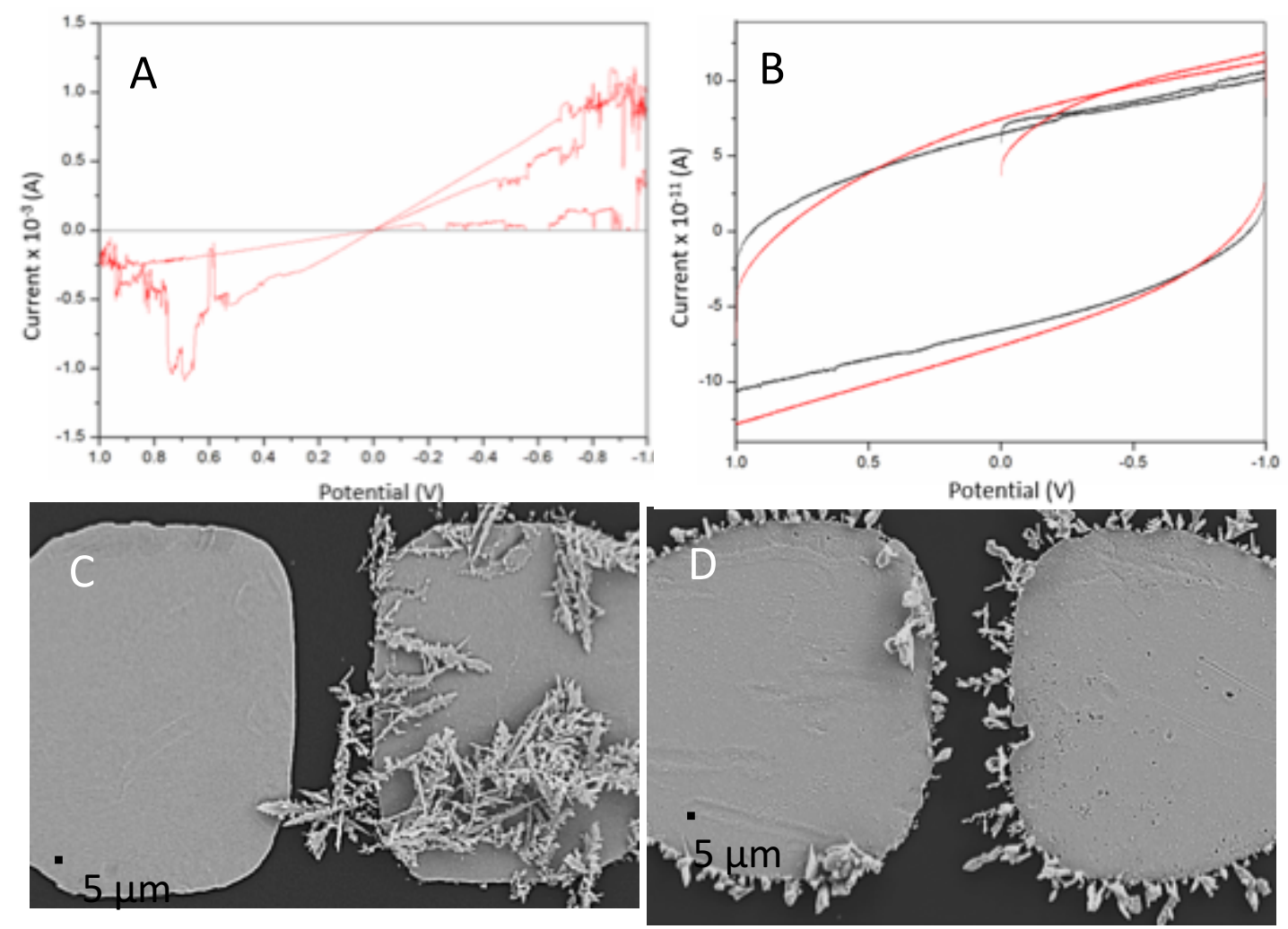

Figure 3.1. (A) i-V curves of the TED device before (black) and after (red) deposition of $\mathrm{Ag}$ nano needles by passing $5 \times 10^{-5} \mathrm{C}$ of charge in 4 seconds, causing the $\mathrm{Ag}$ to cross the electrode gap and make a connection as shown in the SEM image in $C$. (B) i-V curve of TED before (black) and after (red) deposition of Ag nano needles on both sides by passing $1.7 \times 10^{-5} \mathrm{C}$ of charge in 1.5 seconds where the Ag nano needles did not cross the gap. 

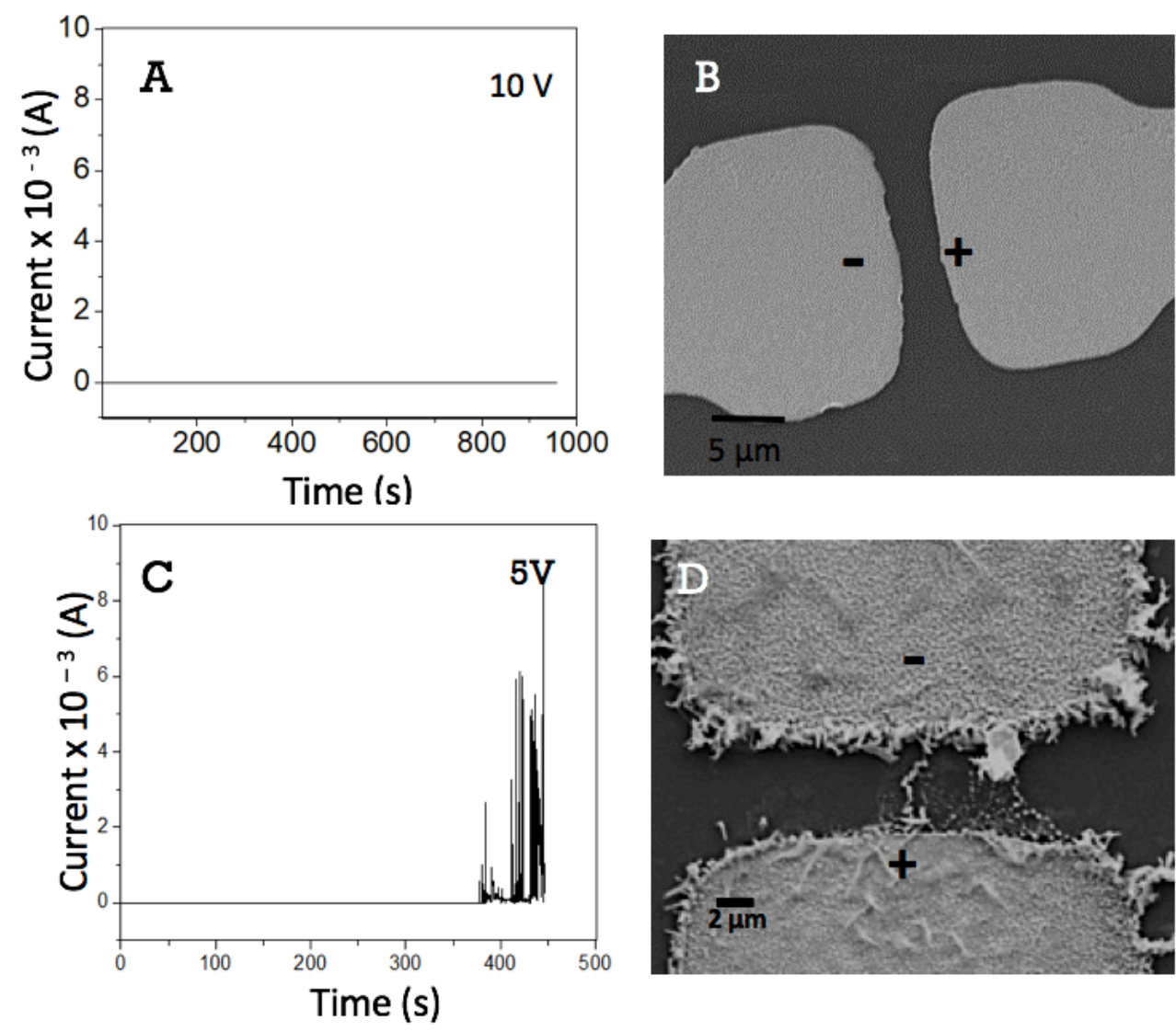

Figure 3.2 A) Current-time plot corresponding to the bare TED device at 10 V. B) SEM of the bare TED with no chains. C) Current- time plot showing the current spikes when $5 \mathrm{~V}$ was applied across the TED D) SEM image of TED Device after Ag deposition, CTAB treatment and application of $5 \mathrm{~V}$ for 450 seconds. Multiple $\mathrm{Ag}$ nanochains were formed across the gap corresponding to the jumps in the current time plot (C). 
When $5 \mathrm{~V}$ was applied across the electrodes deposited with $\mathrm{Ag}$ nanoneedle a series of current spikes appeared due to the applied voltage (Figure $3.2 \mathrm{C}$ ). These corresponding spikes to the formation of multiple Ag NP chains as seen in Figure 3.2 D. The lack of chains with the Au only device confirms that the chains are made of $\mathrm{Ag}$.

Our goal in this study was to control the number, morphology, and current flowing through the connections. For the formation of single $\mathrm{Ag}$ nanochains, we first started with a lower voltage of $1 \mathrm{~V}$ until we either observe a current spike 1000 seconds passes. If no spike was observed, we then stepped to $2 \mathrm{~V}$ for again up to 1000 seconds. This sequence was repeated, going up in $1 \mathrm{~V}$ increments until a current spike occurred. The application of the voltage was abruptly stopped as soon as we saw a spike in current, which means a connection was formed. We believed that starting with a low voltage and slowly moving up would allow us to form single Ag NP chains across the gaps.

Figure 3.3 A shows a current time plot of a TED, with Ag nanowire deposition and CTAB treatment where no chains formed when $1 \mathrm{~V}$ was applied for 1000 seconds. Then $2 \mathrm{~V}$ was applied and a $10^{-3} \mathrm{~A}$ current spike appeared following a small bump of $3.5 \times 10^{-4} \mathrm{~A}$ (Figure $3.3 \mathrm{~B}$ and $\mathrm{C}$ ) near 250 seconds which increased to $10^{-3} \mathrm{~A}$ within 0.5 seconds. The voltage was stopped abruptly after the spike and the current flowing through the device was found to be $10^{-3}$ A from the $\mathrm{i}-\mathrm{V}$ curve from $+1 \mathrm{~V}$ to $-1 \mathrm{~V}$ (Figure $3.3 \mathrm{D}$ ). The chain displaying a current of $10^{-3} \mathrm{~A}$, was a continuous $\mathrm{Ag}$ nanowire as shown in Figure $3.3 \mathrm{E}$ and $3.3 \mathrm{~F}$. 

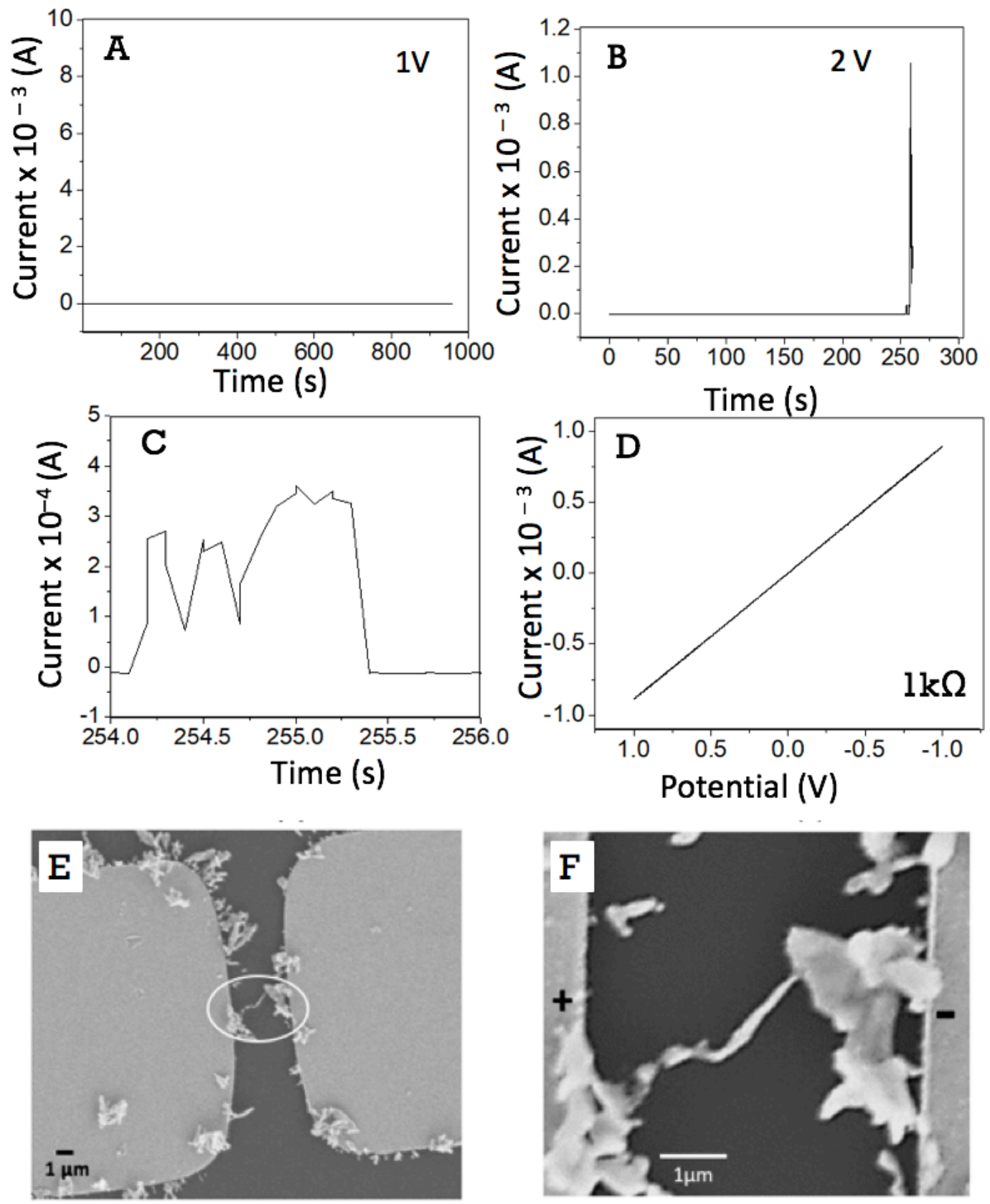

Figure 3.3. A) Current-time plot of the Ag needle deposited TED with no current spikes when $1 \mathrm{~V}$ was applied B) Small current spike (shown by arrow) followed by the $10^{-3} \mathrm{~A}$ spike at 257 seconds at $2 \mathrm{~V}$. C) Zoomed in image of the small spike (shown by arrow in image $A$ ) which is at the $10^{-4} \mathrm{~A}$ level. $\mathrm{D}$ ) $\mathrm{i}$ $\checkmark$ curve of TED after chain formation (E, F) SEM images of the TED. (E) Zoomed in image of the sinale 1D Aa connection. 

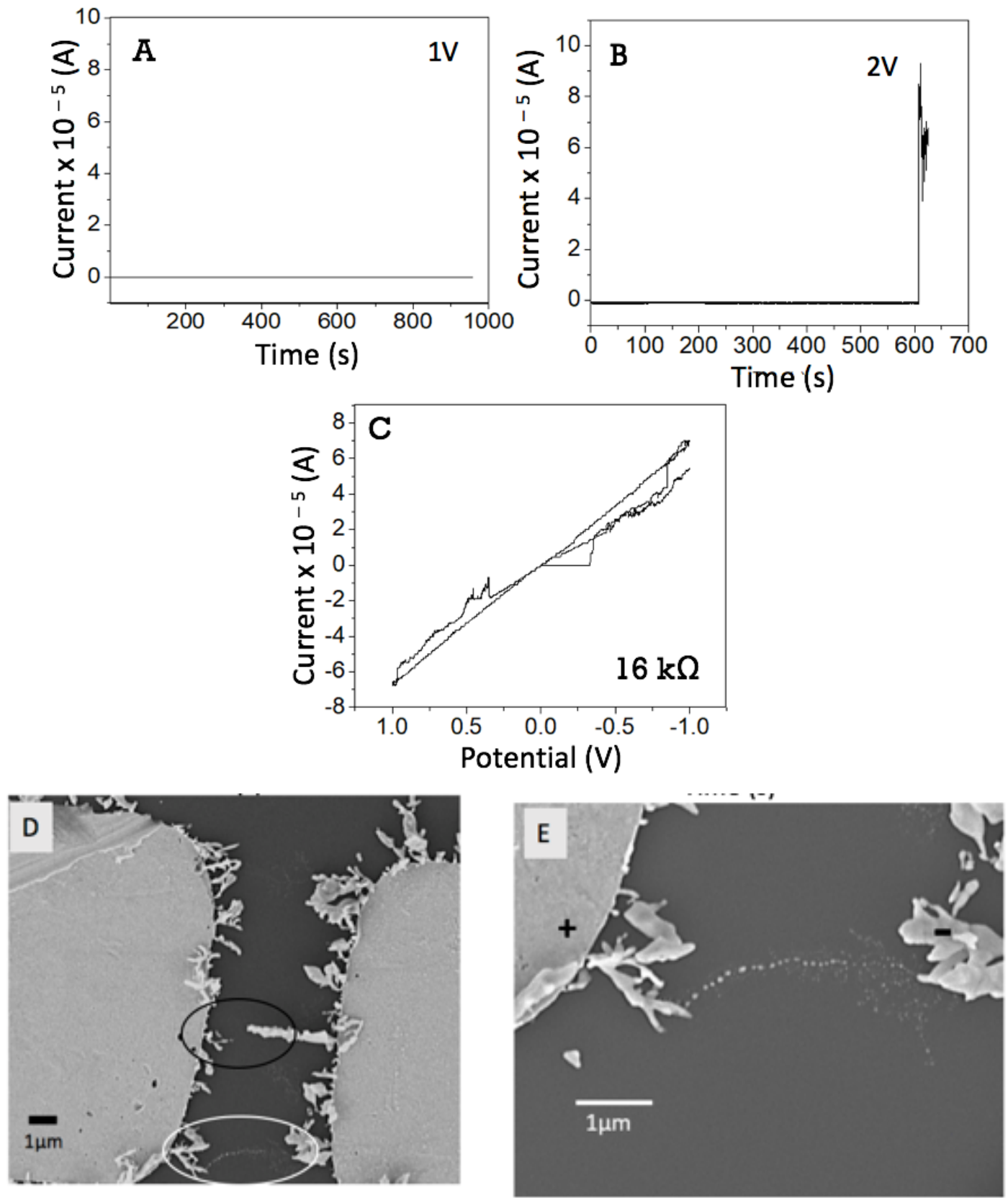

Figure 3.4. A) Current-time plot of Ag nanoneedle TED at $1 \mathrm{~V}$ with no current spikes. B) Current-time plot showing a current spike at 620 seconds with a magnitude of $8 \times 10^{-5} \mathrm{~A}$ when $2 \mathrm{~V}$ was applied across the electrode. C) i-V plot showing the current flowing through the device after i-t plots. D, E) SEM images of TED device with single 1D Ag nanoparticle chains. Black circle shows the apparent shortest electrode gap in image $D$, but no chain formed there. 
Figure 3.4 A shows another sample, where $1 \mathrm{~V}$ was applied for 1000 seconds as before. Since there was no current spike we then applied $2 \mathrm{~V}$, which showed a current spike at 600 seconds of $\sim 8 \times 10^{-5} \mathrm{~A}$, at which the voltage was stopped abruptly. The current flowing through the device was found to be in $10^{-5} \mathrm{~A}$ range from the $\mathrm{i}-\mathrm{V}$ curve (Figure $3.4 . \mathrm{C}$ ). The corresponding SEM image in Figure 3.4 D shows a chain across the gap having well separated very small Ag nanoparticles all along the chain. However, the nanoparticle chain was not found to be formed in between the shortest distance of the needles as shown in Figure 3.4 D as indicated by the black circle. It could be that the needle circled is sticking up away from the electrodes.

Figures 3.3 and 3.4 show two very different connections with different resistance could be formed depending on when the applied voltage is turned off, based on when a spike is observed. It is a bit hard to control. However, in order to better control the amount of current flowing through the single $\mathrm{Ag}$ nanochain connection we altered the strategy a bit. In this strategy, we first applied $1 \mathrm{~V}$ for $1000 \mathrm{~s}$ (or until a spike occurred). Then we applied $2 \mathrm{~V}$ until a current spike occurred. In the sample of Figure 3.5, the current was $5 \times 10^{-6} \mathrm{~A}$ in the i-t plot. After observing the current spike at $2 \mathrm{~V}$, we switched back to a lower voltage of $1 \mathrm{~V}$ to more slowly and controllable fine tune the current. This, resulted in a current of $3 \times 10^{-4} \mathrm{~A}$ within a second of applying the voltage for the sample in Figure $3.5 \mathrm{E}$ and $\mathrm{F}$. This $\mathrm{Ag}$ nanochain had well defined $\mathrm{Ag}$ nanoparticles neatly separated from one another as seen in Figure $3.5 \mathrm{~F}$ and the $\mathrm{Ag}$ nanoparticles seem to have grown bigger than the Ag nanoparticles which had a current of $10^{-5} \mathrm{~A}$ in Figure $3.4 \mathrm{E}$ likely due to the larger current. 
Figure 3.6 shows the current time plots and SEM image of another TED device. As before, no current spike was observed when $1 \mathrm{~V}$ was applied for 1000 seconds. When $2 \mathrm{~V}$ was applied, till a current spike of $1.5 \times 10^{-4} \mathrm{~A}$ appeared, which would correspond to the current caused by as well separated Ag NP chain as in Figure 3.5. When we went back to $1 \mathrm{~V}$, the current level increased to $6 \times 10^{-3} \mathrm{~A}$ due to the formation of a continuous single Ag nanowire (Figure 3.6 A and B). This connection presumably grew from the well interconnected Ag NP chain formed when $2 \mathrm{~V}$ was applied.

Here we proposed two methods for the synthesis of single $\mathrm{Ag}$ nanochains across the microgap of TED. The first involved applying a voltage starting from $1 \mathrm{~V}$ and increasing $1 \mathrm{~V}$ increments until the first current spike appeared, corresponding to a single chain formation. The current level of the chain could not be well controlled in this case. The second method involved the same voltage application starting from $1 \mathrm{~V}$ increments. In this case, once the very first sign of any current spike appeared, the voltage was changed back to $1 \mathrm{~V}$ to fine tune the current level to the desired value. The application of $1 \mathrm{~V}$ at the end allows the connected chain to grow bigger with more current without forming additional new chins across the gap. Table 3.1 shows the overall results from the $\mathrm{i}-\mathrm{V}$ curves and SEM images of the different devices prepared with single $1 \mathrm{D} \mathrm{Ag}$ nanoconnections. Those at the $10^{-3} \mathrm{~A}$ level are well connected wire or rod structures. Those at the $10^{-4} \mathrm{~A}$ level are $1 \mathrm{D}$ chains of $\sim 100 \mathrm{~nm}$ Ag NPs in single file. Those at the $10^{-5} \mathrm{~A}$ level are Ag NP chains of $<$ 50nm diameter NPs. 

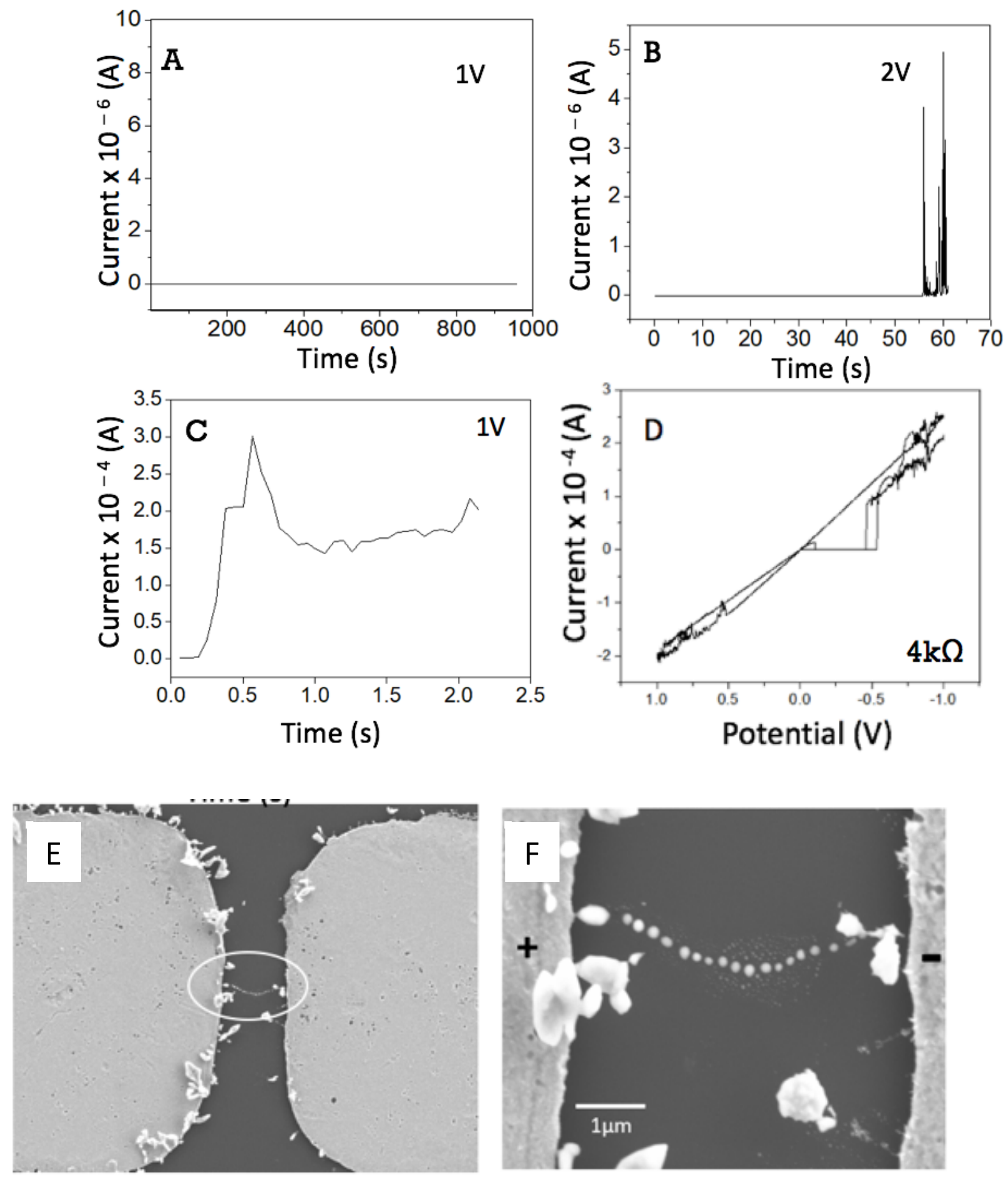

Figure 3.5. (A, B) i-T plots of TED at $1 \mathrm{~V}$ and $2 \mathrm{~V}$ where no spikes were observed when $1 \mathrm{~V}$ was applied and $4 \times 10^{-6} \mathrm{~A}$ current spikes were observed when $2 \mathrm{~V}$ was applied. C) i-t plot after going back to $1 \mathrm{~V} \mathrm{D}$ ) i-V plot showing the final current flow through the TED after chain formation. (E, F) SEM images of the TED after chain formation. 

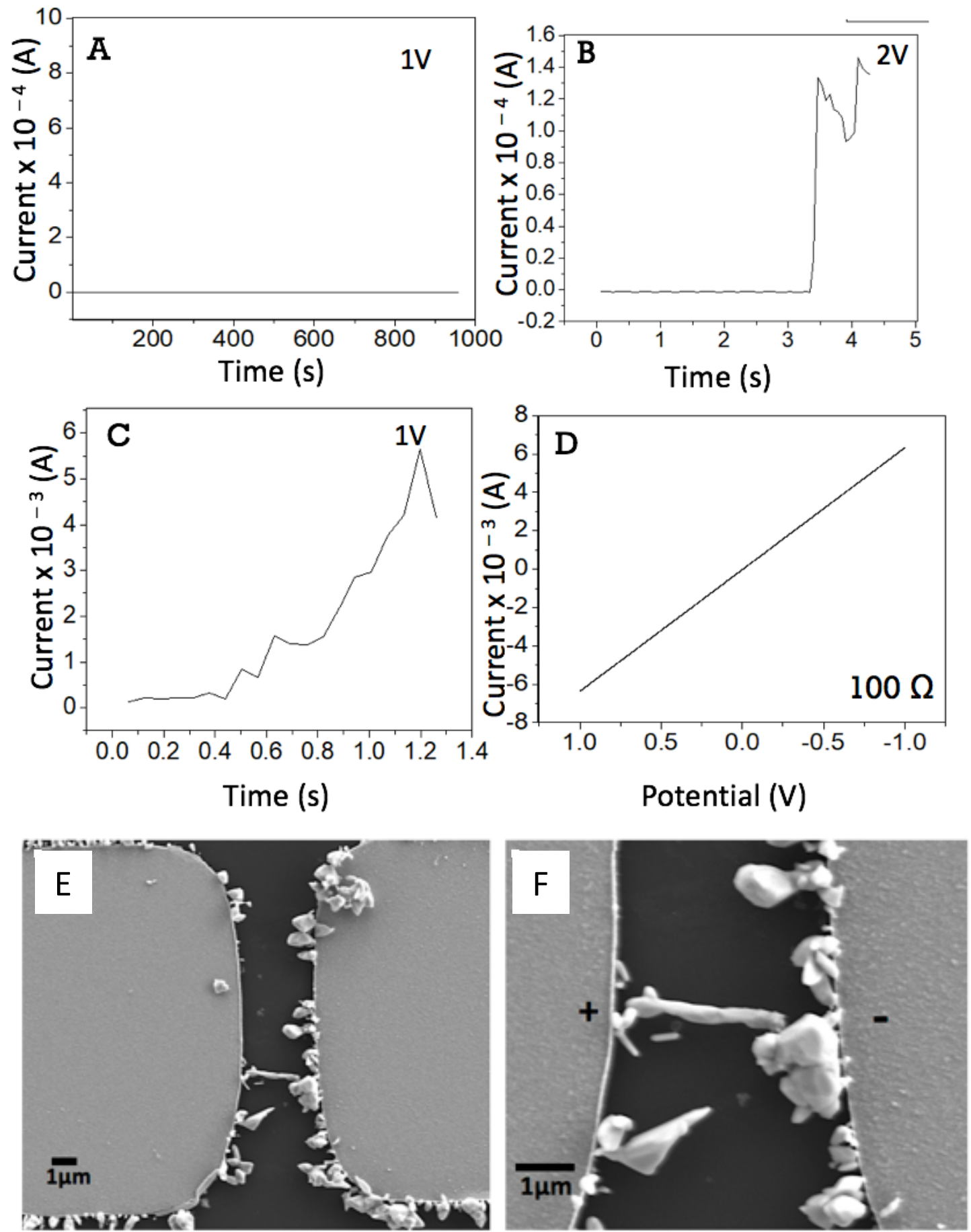

Figure $3.6(\mathrm{~A}, \mathrm{~B})$ i-t plots of TED at $1 \mathrm{~V}, 2 \mathrm{~V}$ and $1 \mathrm{~V}$ where no spikes were observed when $1 \mathrm{~V}$ was applied, $1.4 \times 10^{-4} \mathrm{~A}$ current spikes were observed when $2 \mathrm{~V}$ was applied, which then increased to $6 \times 10^{-3} \mathrm{~A}$ when $1 \mathrm{~V}$ was applied again. D) $\mathrm{i}-\mathrm{V}$ plot showing the current flow in the TED after chain formation. (E, F) SEM images of the single $\mathrm{Ag}$ nanowire type connection across the TED. 
Table 3.1. Overall i-V data and SEM image results of different TEDs with single 1D Nano chains synthesized using Ag needle deposition.

\begin{tabular}{|c|c|c|}
\hline $\begin{array}{c}\text { Voltage(V)applied - } \\
\text { Current }(A) \text { of the spike } \\
\text { in i-T plot }\end{array}$ & $\begin{array}{c}\text { SEM Image of Single } \\
\text { NP Chain }\end{array}$ & $\begin{array}{l}\text { Resistance }(\Omega) / \\
\text { Morphology of } \\
\text { connection }\end{array}$ \\
\hline $\begin{array}{l}\text { Step 1: } 1 \mathrm{~V}-\text { No Spike } \\
\text { Step 2: } 2 \mathrm{~V}-1 \times 10^{-3} \mathrm{~A}\end{array}$ & & 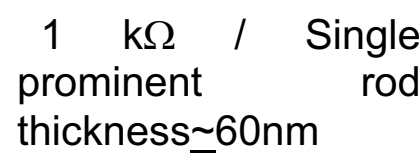 \\
\hline $\begin{array}{l}\text { Step 1: } 1 \mathrm{~V}-\text { No Spike } \\
\text { Step 2: } 2 \mathrm{~V}-8 \times 10^{-5} \mathrm{~A}\end{array}$ & & $\begin{array}{l}16 \mathrm{k} \Omega / \text { Small } \mathrm{Ag} \mathrm{NP} \\
\simeq 40 \mathrm{~nm} \text { chain }\end{array}$ \\
\hline $\begin{array}{l}\text { Step 1: } 1 \mathrm{~V}-\text { No Spike } \\
\text { Step 2: } 2 \mathrm{~V}-6 \times 10^{-6} \mathrm{~A} \\
\text { Step 3: } 1 \mathrm{~V}-2 \times 10^{-4} \mathrm{~A}\end{array}$ & & $4 \mathrm{k} \Omega / \mathrm{Ag} N P \simeq 190 \mathrm{~nm}$ \\
\hline $\begin{array}{l}\text { Step 1: } 1 \mathrm{~V}-\text { No Spike } \\
\text { Step 2: } 2 \mathrm{~V}-5 \times 10^{-6} \mathrm{~A} \\
\text { Step 3: } 1 \mathrm{~V}-3 \times 10^{-4} \mathrm{~A}\end{array}$ & & $4 \mathrm{k} \Omega / \mathrm{Ag} N P \simeq 200 \mathrm{~nm}$ \\
\hline $\begin{array}{l}\text { Step 1: } 1 \mathrm{~V}-\text { No Spike } \\
\text { Step 2: } 2 \mathrm{~V}-1.4 \times 10^{-4} \mathrm{~A} \\
\text { Step 3: } 1 \mathrm{~V}-6 \times 10^{-3} \mathrm{~A}\end{array}$ & & $\begin{array}{l}100 \Omega / \\
\text { Single } \mathrm{Ag} \text { nanorod } \\
\simeq 120 \mathrm{~nm} \text { thick }\end{array}$ \\
\hline $\begin{array}{l}\text { Step 1: } 1 \mathrm{~V}-\text { No Spike } \\
\text { Step 2: } 2 \mathrm{~V}-6 \times 10^{-4} \mathrm{~A} \\
\text { Step 3: } 1 \mathrm{~V}-8 \times 10^{-3} \mathrm{~A}\end{array}$ & & $\begin{array}{l}80 \Omega / \\
\text { Single } \mathrm{Ag} \text { nanorod } \\
\simeq 180 \mathrm{~nm} \text { thick }\end{array}$ \\
\hline
\end{tabular}


From the above study, the current time plot seems to give a good idea about the number of chains formed in the gap and the morphology. Figure 3.7 A shows the i-t plot of a device at $3 \mathrm{~V}$, where a lot of small current spikes in the range of $10^{-7} \mathrm{~A}$ appeared followed by spikes with a current range at $10^{-5} \mathrm{~A}$. As the potential was decreased to $1 \mathrm{~V}$ the current increased to $9 \times 10^{-4} \mathrm{~A}$ and was followed by several small spikes in the range of $1 \times 10^{-4} \mathrm{~A}$ range (Figure $3.7 \mathrm{~B}$ ). Here we would predict that the bigger spike indicates the formation of a good connection and the smaller ones might indicate smaller Ag NP chains. The corresponding SEM image (Figure 3.7 C) shows one prominent Ag nanochain and a few comparatively smaller connections, which we believe to correspond to the smaller spikes in the current- time plot. These multiple chains likely formed as a result of the highly branched morphology of the needles on this electrode.

Sometimes during the deposition of $\mathrm{Ag}$ nanoneedles on both sides of the electrode, we find that the needles fuse to form a well-connected structure even before the application of a voltage in air (Figure 3.8 A). Stopping the deposition at $1.5 \mathrm{~s}$ in order to deposit needles halfway across the gap was a difficult task with $5 \mu \mathrm{m}$ gap. Due to these drawbacks of the Ag needle deposition method, we also tried a different Ag deposition method for the synthesis of single Ag NP 1D chain. It involved the deposition of more uniform Ag NP films on each electrode. The results are described in the next section. 

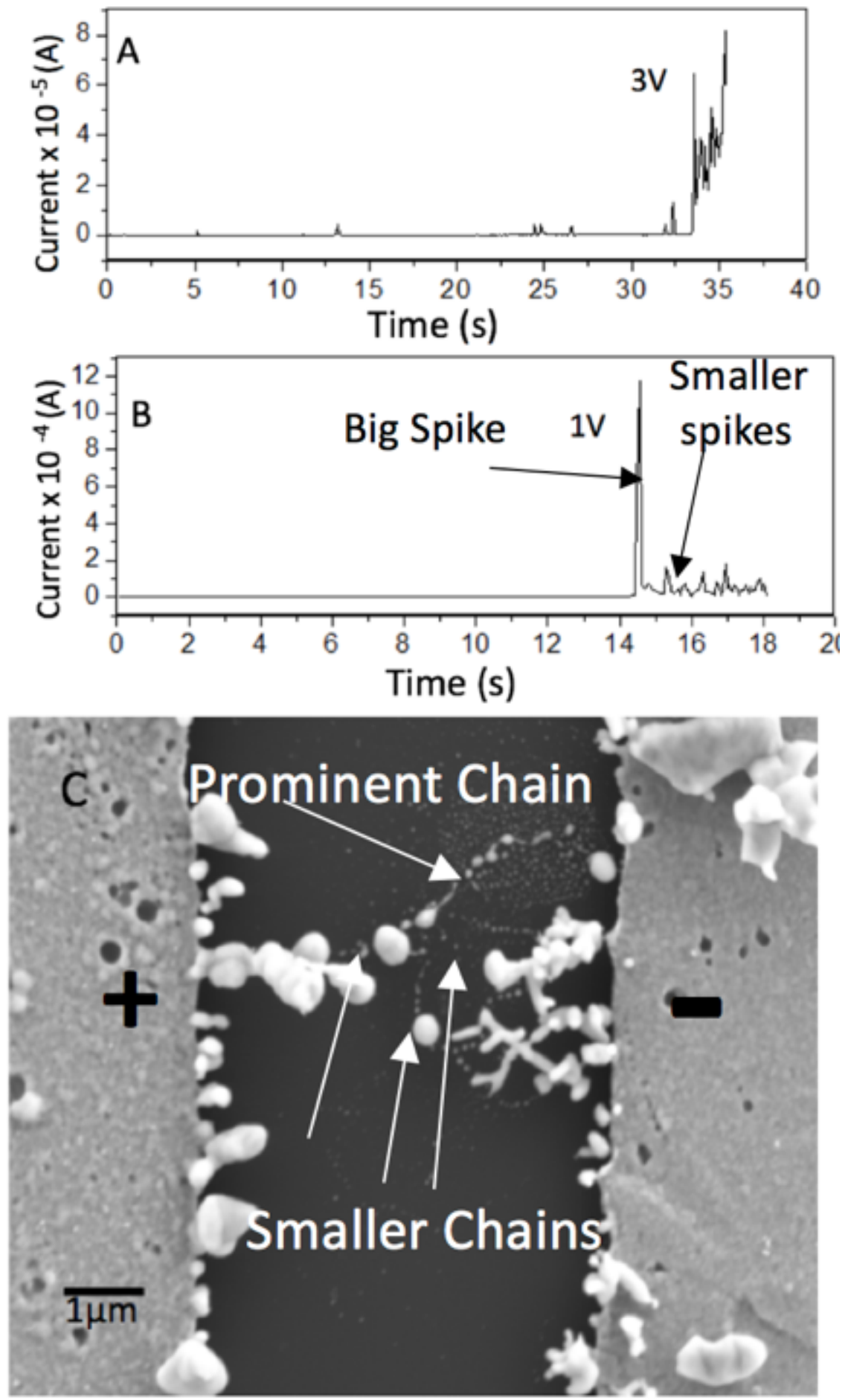

Figure. 3.7. A,B) Current time plots while applying $3 \mathrm{~V}$ and $1 \mathrm{~V}$, where there was a big spike of $9 \times 10^{-4}$ A current followed by several smaller spikes of $10^{-5} \mathrm{~A}$. C) SEM image of the device having one prominent chain and several smaller side chains connecting the nanoneedles on the electrodes. 


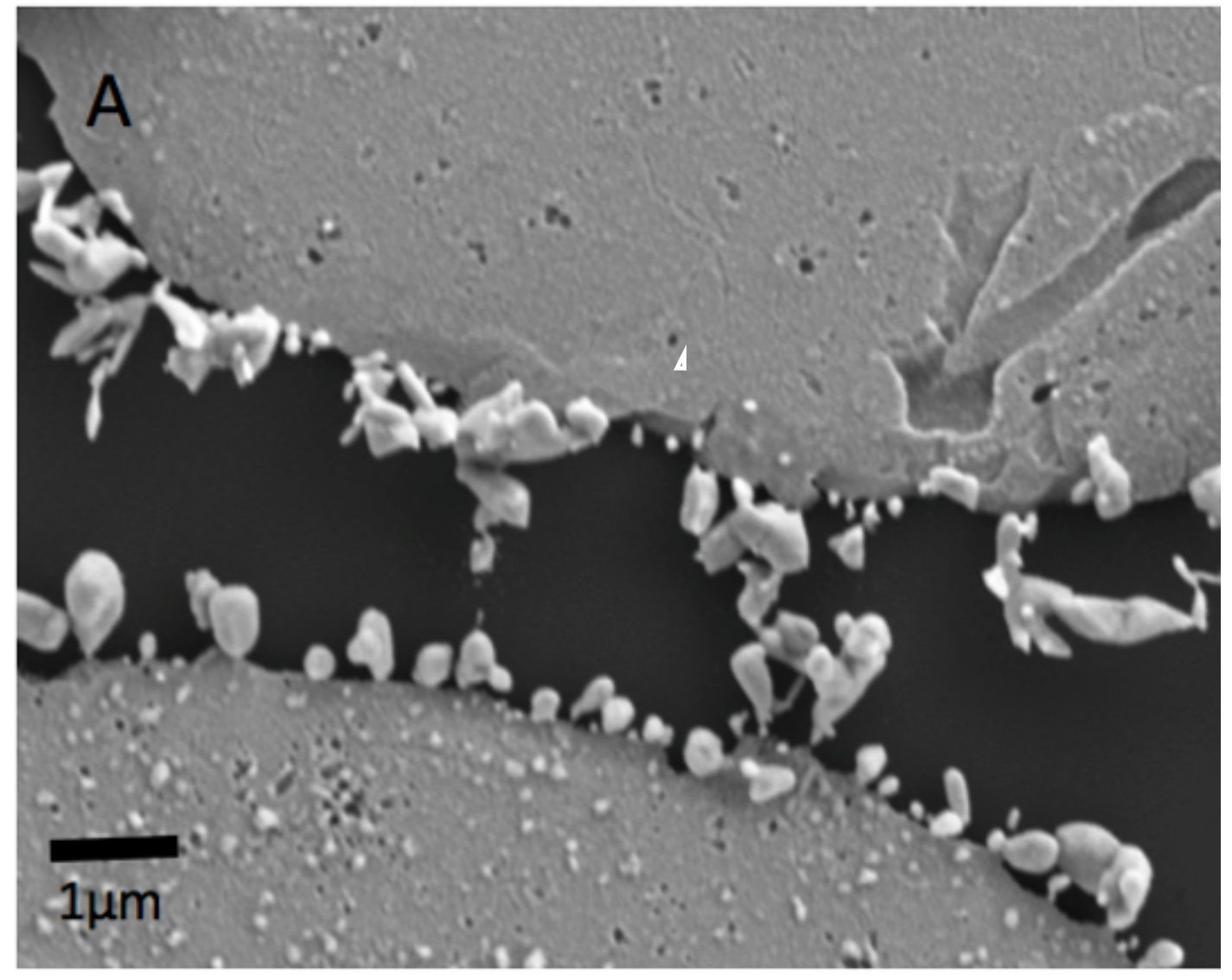

Figure 3.8. A) Completely fused Ag nanoneedles during the deposition process. 


\subsubsection{Ag NP Film Method for Fabrication of Single Ag Nanoparticle Chain Across Microgap Electrodes}

A similar way to synthesize single Ag NP chains was performed on Ag NP films deposited on a TED (with Ag film on both sides). In this case, Ag deposition was carried out at $-0.3 \mathrm{~V}$ in $10 \mathrm{mM} \mathrm{AgNO}_{3}$ in water instead of in 0.1 $\mathrm{M} \mathrm{H}_{2} \mathrm{SO}_{4}$. This leads to Ag deposition in the form of NPs evenly coated on both electrodes instead of $\mathrm{Ag}$ nanoneedles protruding from each electrode. The devices were soaked in $0.1 \mathrm{M} \mathrm{CTAB}$ for 3 hours as before, rinsed with nanopure water for 5 seconds and dried under $\mathrm{N}_{2}$. Figure $3.9 \mathrm{~A}$ shows a current-time plot obtained at $1 \mathrm{~V}$ for $1000 \mathrm{~s}$ and then at $2 \mathrm{~V}$ for the device prepared this way. The current was very low and stable for the entire $1000 \mathrm{~s}$ at $1 \mathrm{~V}$. At $2 \mathrm{~V}$, the current increased to $2.5 \times 10^{-4} \mathrm{~A}$ within 8 seconds (Figure $3.9 \mathrm{~B}$ ). Figure $3.9 \mathrm{C}$ shows the final $\mathrm{i}-\mathrm{V}$ curve of the device. The current was in the $10^{-4} \mathrm{~A}$ level and not ohmic, but clearly a connection was made. The corresponding SEM images in Figure 3.9 D and Figure 3.9 E shows a connection of Ag NPs across the gap that are very broad at the positive electrode but narrower as it reached the negative electrode. While the NPs appear disconnected, the presence of measurable $10^{-4} \mathrm{~A}$ current reveals that they must be connected somehow, possibly through smaller NPs.

Figure 3.10 shows that a device held at $1 \mathrm{~V}$ (Figure $3.10 \mathrm{~A}$ ) and $2 \mathrm{~V}$ (Figure $3.10 \mathrm{~B}$ ) over a longer period of time, having multiple spikes. The SEM images in Figures $3.10 \mathrm{C}, \mathrm{D}$, and $\mathrm{E}$ shows the 5 main connections possibly corresponding to the 5 main peaks in the i-t plot.

As in Figure $3.10 \mathrm{~B}$ the connections were again broad at the positive electrode and narrow at the negative electrode. The 1D NP chains synthesized 

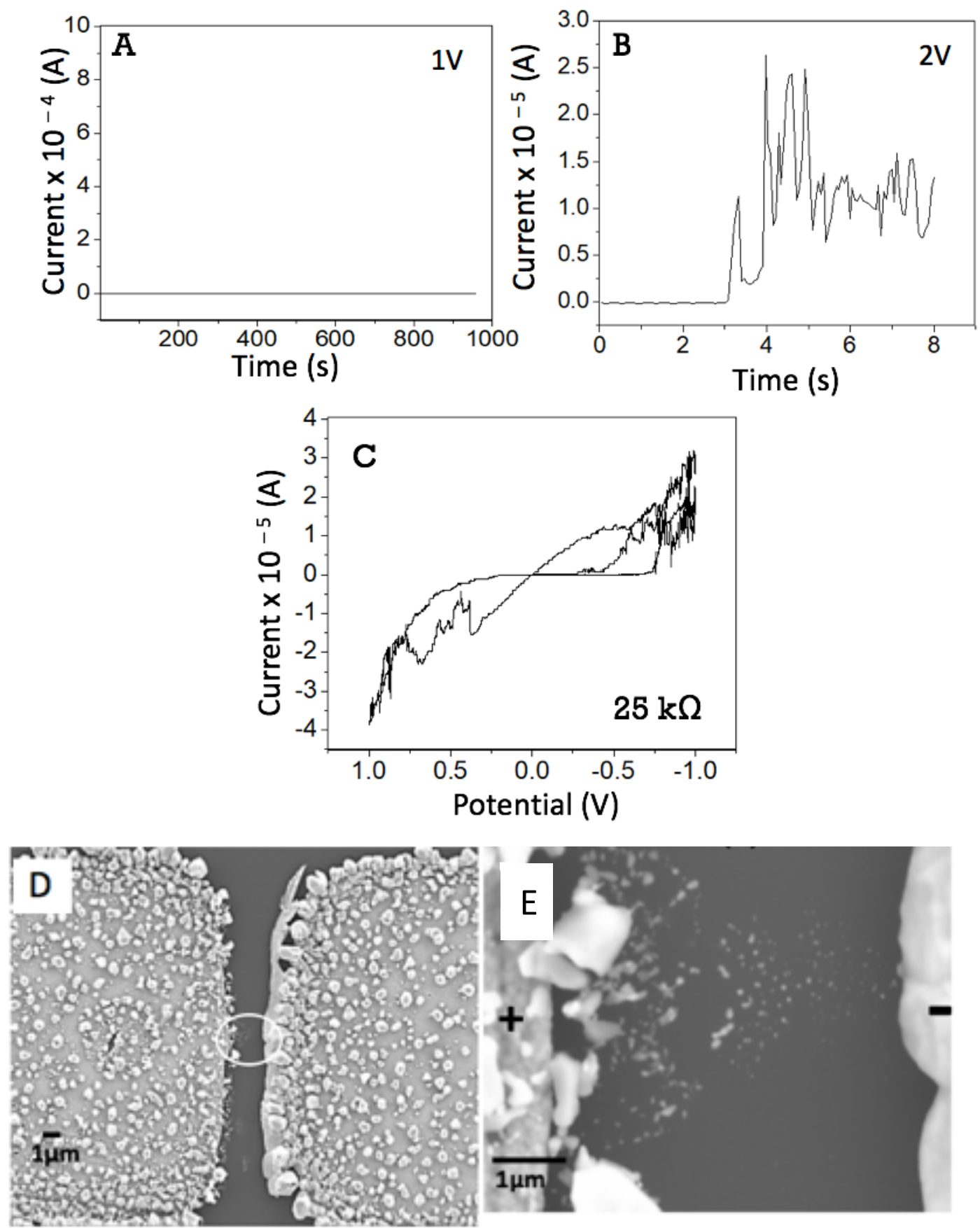

Figure.3.9. A,B) Current time plot of a Ag NP film device soaked in CTAB for 3 hours at $1 \mathrm{~V}$ and $2 \mathrm{~V}$. (C) i-V plot of the TED after chain formation. D,E) SEM images of the device after the current time and i-V plot. Showing a chain connecting the electrodes that are broad at the positive and thin at the negative electrode. 

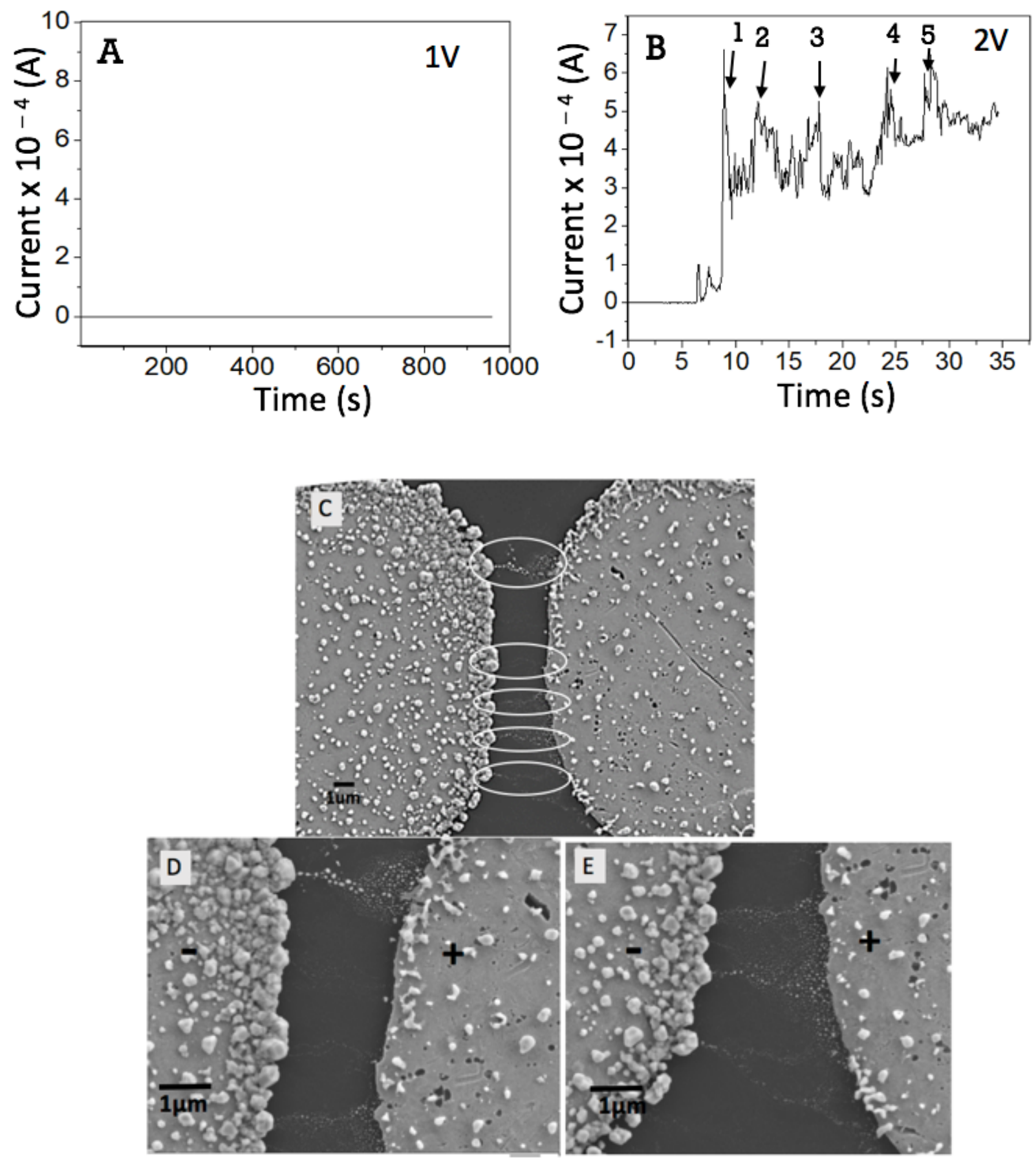

Figure.3.10. (A, B) i-t plot of a Ag NP film device showing no spikes when 1 $\mathrm{V}$ was applied and multiple current spikes when $2 \mathrm{~V}$ was applied over a period of time. (C, D and E) Corresponding SEM images showing multiple 1D chains across the microgap. The arrows and numbers in Figure $B$ correlate with the 5 connections observed in the SEM images. 
using the Ag nanoneedles consisted of well-aligned NPs in a single file since they originally form one of the thin needles. Those from the Ag NP film were broader at the positive electrode (where oxidation occurs) due to the movement of several oxidized $\mathrm{Ag}^{+}$ions in the area, which then became narrower as the $\mathrm{Ag}^{+}$migrated to the negative electrode.

To obtain one single chain, the same strategy was applied as that applied to obtain single chains with Ag needle devices. In the same way after CTAB treatment, a $1 \mathrm{~V}$ potential was applied for 1000 seconds, which usually resulted in no spikes (Figure $3.11 \mathrm{~A}$ ). After $2 \mathrm{~V}$ was applied, we usually observed the first current spike and stopped the voltage immediately. In Figure 3.1.. B, the current jumped to $10^{-5} \mathrm{~A}$ level in just 0.5 seconds at $2 \mathrm{~V}$. Then, we lowered the voltage to $1 \mathrm{~V}$ for some time to make the existing chain grow into bigger particles with a better connected chain. As the voltage was decreased to $1 \mathrm{~V}$, the current increased to $10^{-4} \mathrm{~A}$ within a second (Figure 3.11 C) The final current flowing through the device is shown in Figure 3.11 D. When imaged by SEM (Figure 3.11 E and F) the device showed only one connection where the Ag NPs again were started broader on the positive electrode and eventually became thin as it touched the negative electrode.

Figure $3.12 \mathrm{~B}$ another device. We observed no current at $1 \mathrm{~V}$ but a current spike of $6 \times 10^{-4} \mathrm{~A}$ appeared at $350 \mathrm{~s}$ when $2 \mathrm{~V}$ was applied across the gap (Figure $3.12 \mathrm{~B}$ ). When the potential was decreased to $1 \mathrm{~V}$ again, the current increased to $3 \times 10^{-3} \mathrm{~A}$. The corresponding SEM image (Figure 3.12 (D and E)) show that a chain of Ag NPs formed across the gap that are larger and more connected than those at the $10^{-4} \mathrm{~A}$ level (Figure 3.11 D and E). 

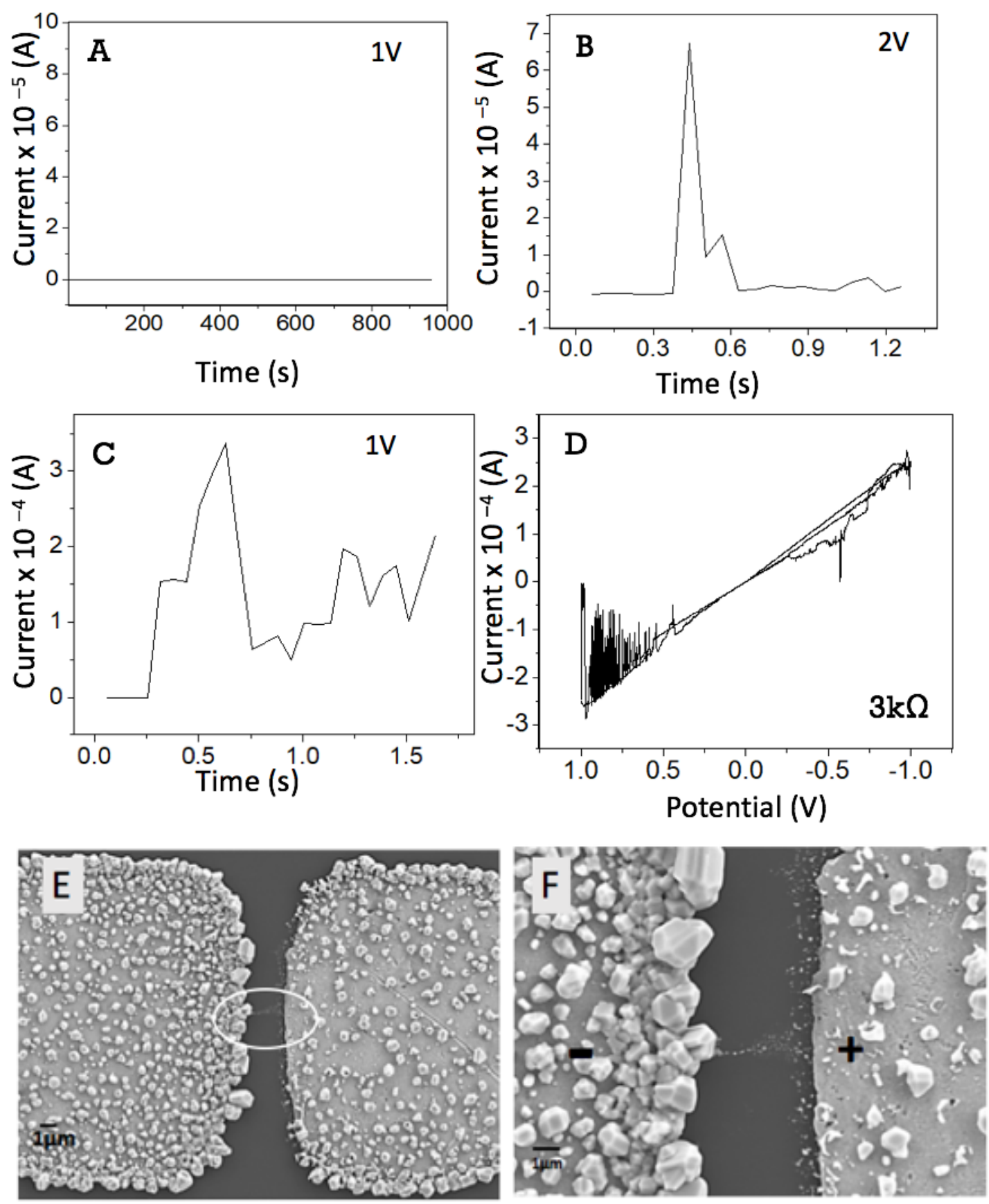

Figure.3.11. (A, B) Current time plots of the device with A) no current spike at $1 \mathrm{~V}$ and $B$ ) Single current spike of magnitude $10^{-5} \mathrm{~A}$ at a potential of $2 \mathrm{~V}$ C) The current increased to $10^{-4} \mathrm{~A}$ when a potential of $1 \mathrm{~V}$ was applied. $\mathrm{D}$ ) $\mathrm{i}-\mathrm{V}$ plot showing the final current flowing through the device. E) SEM image of the whole device with a single Ag NP connection. F) Zoomed in view of the Ag NP chain. 

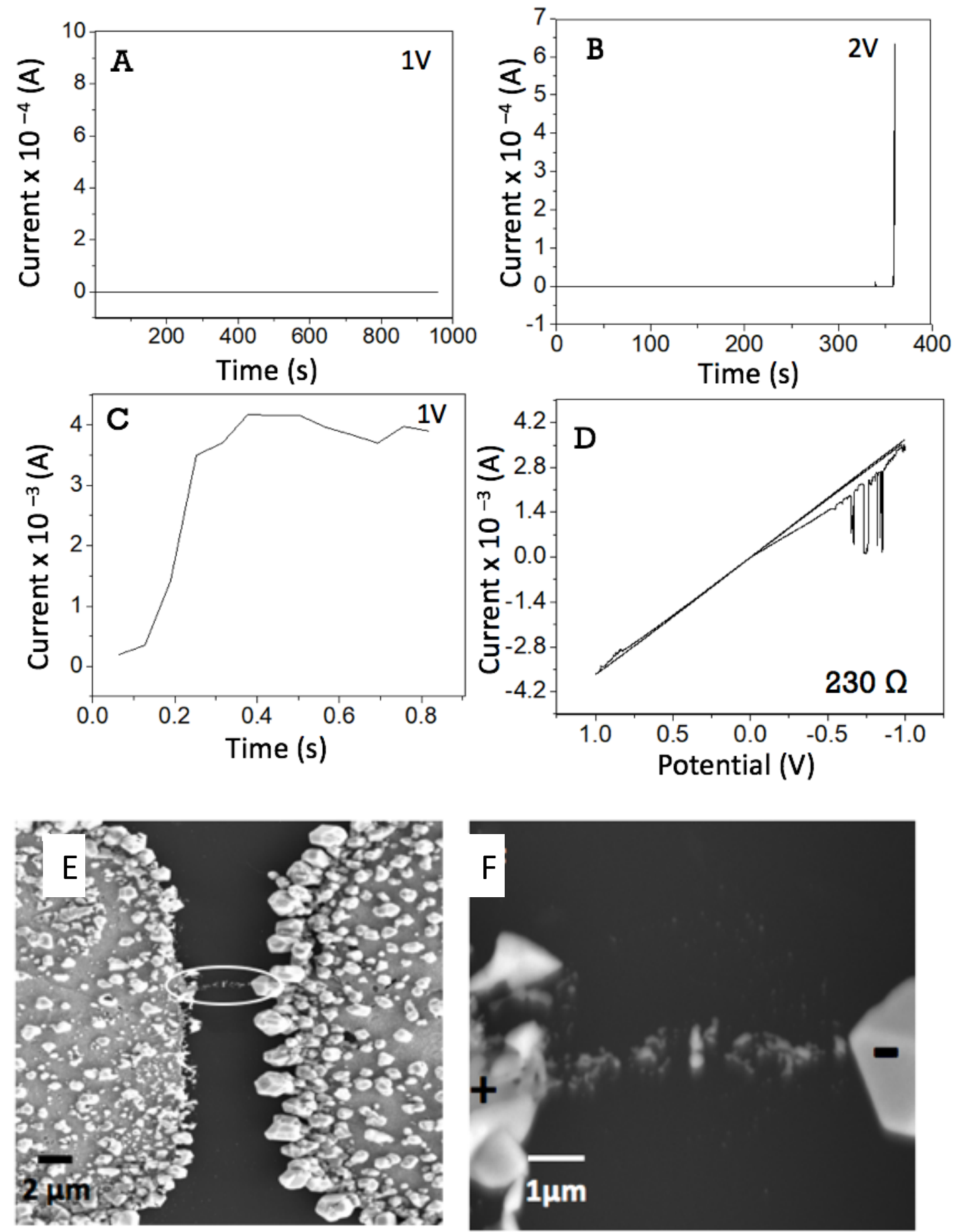

Figure.3.12. Current time plots of the device with $A$ ) no current spike when 1 $\mathrm{V}$ was applied. B) Single current spike at $350 \mathrm{~s}$ of $10^{-4} \mathrm{~A}$ at a potential $2 \mathrm{~V} \mathrm{C}$ ) Current spike increased to $10^{-3} \mathrm{~A}$ when $1 \mathrm{~V}$ was again applied. D) i-V plot showing the final current flowing through the device. E) SEM image of the gap area showing a single connection. F) Zoomed in view of the Ag NP chain. 
Table 3.2. Electronic properties and SEM images of the various 1D Ag NP chains using Ag NP deposition method.

\begin{tabular}{|c|c|}
\hline $\begin{array}{c}\text { Voltage (V)-Current of } \\
\text { spike (A) }\end{array}$ & SEM Image of single 1D NP chain \\
\hline $\begin{array}{l}\text { Step 1: } 1 \mathrm{~V}-\text { No Current } \\
\text { Step 2: } 2 \mathrm{~V}-1 \times 10^{-5} \mathrm{~A} \\
\text { Step 3: } 1 \mathrm{~V}-1.4 \times 10^{-4} \mathrm{~A}\end{array}$ & \\
\hline $\begin{array}{l}\text { Step 1: } 1 \mathrm{~V} \text {-No Current } \\
\text { Step 2: } 2 \mathrm{~V}-3 \times 10^{-5} \mathrm{~A} \\
\text { Step } 3: 1 \mathrm{~V}-1.5 \times 10^{-4} \mathrm{~A}\end{array}$ & \\
\hline $\begin{array}{l}\text { Step 1: } 1 \mathrm{~V}-\text { No Current } \\
\text { Step 2: } 2 \mathrm{~V}-6 \times 10^{-5} \mathrm{~A} \\
\text { Step 3:1 V- } 3 \times 10^{-4} \mathrm{~A}\end{array}$ & \\
\hline $\begin{array}{l}\text { Step 1: } 1 \mathrm{~V}-\text { No Current } \\
\text { Step 2: } 2 \mathrm{~V}-6 \times 10^{-4} \mathrm{~A} \\
\text { Step 3:1 V- } 4 \times 10^{-3} \mathrm{~A}\end{array}$ & \\
\hline $\begin{array}{l}\text { Step1: } 1 \mathrm{~V}-\text { No Current } \\
\text { Step 2: } 2 \mathrm{~V}-1.4 \times 10^{-4} \mathrm{~A} \\
\text { Step 3: } 1 \mathrm{~V}-5 \times 10^{-3} \mathrm{~A}\end{array}$ & \\
\hline
\end{tabular}


We wanted to determine the reproducibility of the method on different devices with the similar Ag NP film deposition and CTAB treatment. These resulted in single 1D NP chains across the TED which has been summarised in Table 3.2. The currents measured through the device were controlled by the time of applying the second $1 \mathrm{~V}$ application. The chain morphologies match the measured current.

\subsection{Conclusions}

We controlled the formation of single Ag NP chains across Au microgap electrodes separated by a $5 \mu \mathrm{m}$ distance. Our study clearly indicates that single Ag nanoparticle chains can be fabricated by monitoring the current time plot starting at lower voltages and slowly increasing the voltage. Initially the NP chains were fabricated by applying a lower potential and then stepping gradually to higher voltages until a current spike was observed. This resulted in single chains, but resulted in current spikes uncontrollably in the $10^{-5}$ to $10^{-3}$ A range. Later, the NP chains with a higher current level were fabricated by applying $1 \mathrm{~V}$ after the chain formed in order to make the NPs of the chain grow into larger particles, but still remaining as a single NP chain.

In one method, the chains were fabricated using electrodes with Ag nanoneedles electrodeposited on both sides of the electrode. The deposition of the needles usually took about 1.2 seconds by chronocoulometry and it was a bit difficult to stop the deposition within that time limit. The needles also grew at random positions on the electrode, which was not very controllable, and they sometimes fused, making a direct connection. Although the needles grew into the microgap, the chain formation was not always at the needles with the shortest distance gap, which possibly indicates that different amounts of CTAB 
are present at different locations of the electrode gap. With the nanoneedles the Ag NP chains are uniform and in single file in the $10^{-4} \mathrm{~A}$ to $10^{-5} \mathrm{~A}$ level and a continuous wire in the $10^{-3} \mathrm{~A}$ level.

In the second method, Ag was electrodeposited using $10 \mathrm{mM} \mathrm{AgNO}_{3}$ in water, which led to a more uniform deposition of Ag over the electrode. This took about 5 seconds for the deposition of $6 \times 10^{-5} \mathrm{C}$ and was much easier to control as compared to 1.6 seconds for the $\mathrm{Ag}$ needle deposition. It also minimized the risk of forming direct connections during deposition. The single Ag NP chains could be fabricated by monitoring the current time plot at lower voltages and by lowering the voltage to $1 \mathrm{~V}$ after chain formation. The current of these Ag NP chains were well-controlled but the morphology was not as uniform. The connected Ag NP chains were broad at the positive electrode and narrow at the negative electrode (cone shaped) and continuous nanowires were formed. 


\section{CHAPTER IV}

\section{SUMMARY AND FUTURE DIRECTIONS}

\subsection{Summary}

This study describes an electrochemical approach for the synthesis of single 1D Ag NP chains between a $5 \mu \mathrm{m}$ gap TED. This technique is a reliable, rapid, and template free fabrication method enabled by combining electrochemistry and microfabrication. The chains were formed by an electrochemical process where the metal was oxidized at the positive electrode and deposited at the negative electrode under an applied potential in the presence of CTAB and humid air. The potential applied and current spikes observed in the current time plot allowed control of the single 1D chains. Lower potentials lead to the formation of single NP chains showing a current spike in the current-time plot. The potential was quickly stopped at this point to achieve a single NP chain. A lower voltage $(1 \mathrm{~V})$ was then applied to control the chain morphology and conductivity. Electrodeposited Ag nanoneedles led to uniform Ag NPs in a single file or continuous wires, while electrodeposited Ag NP films led to cone shaped chain assemblies.

\subsection{Future Fundamental Studies}

Apart from the potential applications in chemical sensing, molecular and nano electronics, these single 1D chains could be used for Surface Enhanced Raman Scattering (SERS) and Localized Surface Plasmon Resonance (LSPR) studies. 
The resistive switching behavior of these devices would be interesting as they might show different switching behavior at different current levels, which we can control. Surface Enhanced Raman Spectroscopy (SERS) and Localized Surface Plasmon Spectroscopy (LSPR) measurements during resistive switching of these $1 \mathrm{D}$ chains would be very interesting. The development of these 1D nanochains with different metals, such as $\mathrm{Cu}, \mathrm{Pd}$ and $\mathrm{Ni}$, could also be developed in the same way for nanoscale chemical sensing, nanoelectronics, and memory storage device applications. 


\section{REFERENCES}

1. Shah, N.; Zamborini, F. P., ACS Nano 2015, 9 (10), 10278-10286.

2. Rao, C. N.; Kulkarni, G. U.; Thomas, P. J.; Edwards, P. P., Chemistry 2002, 8 (1), 28-35.

3. Schuller, J. A.; Barnard, E. S.; Cai, W.; Jun, Y. C.; White, J. S.;

Brongersma, M. L., Nat Mater 2010, 9 (3), 193-204.

4. Shalaev, V. M., Science 2008, 322 (5900), 384-6.

5. Pengo, P.; Baltzer, L.; Pasquato, L.; Scrimin, P., Angew. Chem. Int. Ed. Engl. 2007, 46 (3), 400-4.

6. El-Sayed, I. H.; Huang, X.; El-Sayed, M. A., Nano Lett. 2005, 5 (5), 829-34.

7. El-Sayed, I. H.; Huang, X.; El-Sayed, M. A., Cancer Lett 2006, 239 (1), 129-35.

8. $\quad$ Li, J. F.; Zhang, Y. J.; Ding, S. Y.; Panneerselvam, R.; Tian, Z. Q., Chem. Rev. 2017.

9. $\quad$ Yang, Z.; Chen, S.; Fang, P.; Ren, B.; Girault, H. H.; Tian, Z., Phys.

Chem. Chem. Phys. 2013, 15 (15), 5374-8.

10. Lee, J.; Pang, Y., J Nanosci Nanotechnol 2016, 16 (2), 1629-32.

11. Kim, K.; Lee, Y. M.; Lee, J. W.; Shin, K. S., Langmuir 2009, 25 (5), $2641-5$.

12. Leontidis, E.; Kleitou, K.; Kyprianidou-Leodidou, T.; Bekiari, V.; Lianos,

P., Langmuir 2002, 18 (9), 3659-3668. 
13. Koczkur, K. M.; Mourdikoudis, S.; Polavarapu, L.; Skrabalak, S. E., Dalton Transactions 2015, 44 (41), 17883-17905.

14. Wiley, B.; Sun, Y.; Xia, Y., Acc. Chem. Res. 2007, 40 (10), 1067-1076.

15. Wiley, B.; Sun, Y.; Mayers, B.; Xia, Y., Chemistry-A European Journal 2005, $11(2), 454-463$.

16. Sun, Y.; Xia, Y., Science 2002, 298 (5601), 2176-2179.

17. Bratlie, K. M.; Lee, H.; Komvopoulos, K.; Yang, P.; Somorjai, G. A., Nano Lett. 2007, 7 (10), 3097-3101.

18. Song, H.; Kim, F.; Connor, S.; Somorjai, G. A.; Yang, P., The Journal of Physical Chemistry B 2005, 109 (1), 188-193.

19. Rioux, R. M.; Song, H.; Grass, M.; Habas, S.; Niesz, K.; Hoefelmeyer,

J. D.; Yang, P.; Somorjai, G. A., Top. Catal. 2006, 39 (3), 167-174.

20. Jin, R.; Egusa, S.; Scherer, N. F., J. Am. Chem. Soc. 2004, 126 (32), 9900-9901.

21. Li, C.; Shuford, K. L.; Park, Q.; Cai, W.; Li, Y.; Lee, E. J.; Cho, S. O., Angew. Chem. 2007, 119 (18), 3328-3332.

22. Yihai, W.; Penglei, C.; Minghua, L., Nanotechnology 2006, 17 (24), 6000.

23. Jin, M.; He, G.; Zhang, H.; Zeng, J.; Xie, Z.; Xia, Y., Angew. Chem. Int. Ed. 2011, 50 (45), 10560-10564.

24. Jana, N. R.; Gearheart, L.; Murphy, C. J., Chem. Mater. 2001, 13 (7), 2313-2322.

25. Nikoobakht, B.; El-Sayed, M. A., Chem. Mater. 2003, 15 (10), 19571962. 
26. Murphy, C. J.; Sau, T. K.; Gole, A. M.; Orendorff, C. J.; Gao, J.; Gou, L.; Hunyadi, S. E.; Li, T., J. Phys. Chem. B 2005, 109 (29), 13857-13870.

27. Reetz, M. T.; Winter, M.; Breinbauer, R.; Thurn-Albrecht, T.; Vogel, W., Chemistry-A European Journal 2001, 7 (5), 1084-1094.

28. Yu; Chang, S.-S.; Lee, C.-L.; Wang, C. R. C., The Journal of Physical Chemistry B 1997, 101 (34), 6661-6664.

29. Dasari, R.; Zamborini, F. P., J. Am. Chem. Soc. 2008, 130 (48), 1613816139.

30. Dasari, R.; Zamborini, F. P., Anal. Chem. 2016, 88 (1), 675-681.

31. Rycenga, M.; Cobley, C. M.; Zeng, J.; Li, W.; Moran, C. H.; Zhang, Q.; Qin, D.; Xia, Y., Chem. Rev. 2011, 111 (6), 3669-3712.

32. Zhao, L.; Kelly, K. L.; Schatz, G. C., The Journal of Physical Chemistry B 2003, 107 (30), 7343-7350.

33. Silambarasan, K.; Narendra Kumar, A. V.; Sivakumar, C.; Joseph, J., RSC Advances 2014, 4 (75), 40003-40007.

34. Chen, H.; Shao, L.; Li, Q.; Wang, J., Chem. Soc. Rev. 2013, 42 (7), 2679-2724.

35. Sahoo, S.; Husale, S.; Karna, S.; Nayak, S. K.; Ajayan, P. M., J. Am. Chem. Soc. 2011, 133 (11), 4005-4009.

36. Ben Ali, M.; Ondarçuhu, T.; Brust, M.; Joachim, C., Langmuir 2002, 18 (3), 872-876.

37. Wang, W. M.; Stoltenberg, R. M.; Liu, S.; Bao, Z., ACS Nano 2008, 2 (10), 2135-2142.

38. Chen, J.; Sun, Y.; Zhong, L.; Shao, W.; Huang, J.; Liang, F.; Cui, Z.; Liang, Z.; Jiang, L.; Chi, L., Small 2016, 12 (42), 5818-5825. 
39. Costner, E. A.; Lin, M. W.; Jen, W.-L.; Willson, C. G., Annual Review of Materials Research 2009, 39 (1), 155-180.

40. Scappucci, G.; Capellini, G.; Johnston, B.; Klesse, W. M.; Miwa, J. A.; Simmons, M. Y., Nano Lett. 2011, 11 (6), 2272-2279.

41. Maier, S. A.; Brongersma, M. L.; Atwater, H. A., Appl. Phys. Lett. 2001, $78(1), 16-18$.

42. Alivisatos, A. P.; Johnsson, K. P.; Peng, X.; Wilson, T. E.; Loweth, C. J.; Bruchez, M. P.; Schultz, P. G., Nature 1996, 382, 609.

43. Tan, S. J.; Campolongo, M. J.; Luo, D.; Cheng, W., Nat Nano 2011, 6 (5), 268-276.

44. Pardatscher, G.; Bracha, D.; Daube, S. S.; Vonshak, O.; Simmel, F. C.; Bar-Ziv, R. H., Nat Nano 2016, 11 (12), 1076-1081.

45. Niemeyer, C. M.; Simon, U., Eur. J. Inorg. Chem. 2005, 2005 (18), 3641-3655.

46. Catherall, T.; Huskisson, D.; McAdams, S.; Vijayaraghavan, A., Journal of Materials Chemistry C 2014, 2 (34), 6895-6920.

47. Hamada, D.; Yanagihara, I.; Tsumoto, K., Trends Biotechnol. 22 (2), 93-97.

48. Banerjee, I. A.; Yu, L.; Matsui, H., Proceedings of the National Academy of Sciences 2003, 100 (25), 14678-14682.

49. Dujardin, E.; Peet, C.; Stubbs, G.; Culver, J. N.; Mann, S., Nano Lett. 2003, 3 (3), 413-417.

50. Fullam, S.; Cottell, D.; Rensmo, H.; Fitzmaurice, D., Adv. Mater. 2000, $12(19), 1430-1432$. 
51. Male, K. B.; Hrapovic, S.; Liu, Y.; Wang, D.; Luong, J. H. T., Anal. Chim. Acta 2004, 516 (1), 35-41.

52. Mu, Y.; Liang, H.; Hu, J.; Jiang, L.; Wan, L., The Journal of Physical Chemistry B 2005, 109 (47), 22212-22216.

53. Hrapovic, S.; Liu, Y.; Male, K. B.; Luong, J. H. T., Anal. Chem. 2004, $76(4), 1083-1088$.

54. Ang, L.-M.; Hor, T. S. A.; Xu, G.-Q.; Tung, C.-h.; Zhao, S.; Wang, J. L. S., Chem. Mater. 1999, 11 (8), 2115-2118.

55. Yang, M.; Chen, G.; Zhao, Y.; Silber, G.; Wang, Y.; Xing, S.; Han, Y.; Chen, H., PCCP 2010, 12 (38), 11850-11860.

56. Han, X.; Goebl, J.; Lu, Z.; Yin, Y., Langmuir 2011, 27 (9), 5282-5289.

57. Gangula, A.; Chelli, J.; Bukka, S.; Poonthiyil, V.; Podila, R.; Kannan,

R.; Rao, A. M., J. Mater. Chem. 2012, 22 (43), 22866-22872.

58. Sardar, R.; Shumaker-Parry, J. S., Nano Lett. 2008, 8 (2), 731-736.

59. Walter, M. V.; Cheval, N.; Liszka, O.; Malkoch, M.; Fahmi, A., Langmuir 2012, 28 (14), 5947-5955.

60. Tan, Y.; Jiang, L.; Li, Y.; Zhu, D., The Journal of Physical Chemistry B 2002, 106 (12), 3131-3138.

61. Hucht, A.; Buschmann, S.; Entel, P., EPL 2007, 77 (5), 57003.

62. Barsotti, R. J.; Vahey, M. D.; Wartena, R.; Chiang, Y.-M.; Voldman, J.; Stellacci, F., Small 2007, 3 (3), 488-499.

63. Pescaglini, A.; O'Riordan, A.; Quinn, A. J.; lacopino, D., Journal of Materials Chemistry C 2014, 2 (33), 6810-6816.

64. Tang, Z.; Kotov, N. A., Adv. Mater. 2005, 17 (8), 951-962.

65. Nie, Z.; Petukhova, A.; Kumacheva, E., Nat Nano 2010, 5 (1), 15-25. 
66. Ozbay, E., Science 2006, 311, 189.

67. Maier, S. A.; Brongersma, M. L.; Kik, P. G.; Meltzer, S.; Requicha, A.

A. G.; Atwater, H. A., Adv. Mater. 2001, 13 (19), 1501-1505.

68. Dasari, R.; Ibañez, F. J.; Zamborini, F. P., Langmuir 2011, 27, 7285.

69. Cheon, D.; Kumar, S.; Kim, G.-H., Appl. Phys. Lett. 2010, 96 (1), 013101

70. Kretschmer, R.; Fritzsche, W., Langmuir 2004, 20 (26), 11797-11801.

71. Ranjan, N.; Mertig, M.; Cuniberti, G.; Pompe, W., Langmuir 2010, 26

(1), 552-559.

72. Venkatesh, R.; Kundu, S.; Pradhan, A.; Sai, T. P.; Ghosh, A.;

Ravishankar, N., Langmuir 2015, 31 (33), 9246-9252.

73. Ding, H.; Liu, W.; Ding, Y.; Shao, J.; Zhang, L.; Liu, P.; Liu, H., RSC Advances 2015, 5 (8), 5523-5532.

74. Maier, S. A.; Kik, P. G.; Atwater, H. A.; Meltzer, S.; Harel, E.; Koel, B.

E.; Requicha, A. A. G., Nat Mater 2003, 2 (4), 229-232.

75. Maier, S.; Brongersma, M.; Kik, P.; Meltzer, S.; Requicha, A.; Koel, B.; Atwater, H., Adv. Mater. 2003, 15 (7-8), 562-562.

76. Kong, J.; Chapline, M. G.; Dai, H., Adv. Mater. 2001, 13 (18), 1384.

77. Kim, K. T.; Sim, J.; Cho, S. M., IEEE Sens. J. 2006, 6 (3), 509-513.

78. Im, Y.; Lee, C.; Vasquez, R. P.; Bangar, M. A.; Myung, N. V.; Menke, E. J.; Penner, R. M.; Yun, M., Small 2006, 2 (3), 356-358.

79. Lee, J.; Mubeen, S.; Hangarter, C. M.; Mulchandani, A.; Chen, W.; Myung, N. V., Electroanalysis 2011, 23 (11), 2623-2628.

80. Maier, S. A.; Kik, P. G.; Atwater, H. A., Physical Review B 2003, 67 (20), 205402. 
81. Krenn, J. R., Nature Materials 2003, 2 (4), 210-211.

82. Shimada, T.; Ookubo, K.; Komuro, N.; Shimizu, T.; Uehara, N., Langmuir 2007, 23 (22), 11225-11232.

83. Barber, D.; Freestone, I. C., Archaeometry 1990, 32 (1), 33-45.

84. Waser, R.; Aono, M., Nature materials 2007, 6 (11), 833-840.

85. Schirm, C.; Matt, M.; Pauly, F.; Cuevas, J. C.; Nielaba, P.; Scheer, E., Nature nanotechnology 2013, 8 (9), 645-648.

86. Kitaguchi, Y.; Habuka, S.; Okuyama, H.; Hatta, S.; Aruga, T.;

Frederiksen, T.; Paulsson, M.; Ueba, H., Beilstein Journal of Nanotechnology 2015, 6, 2088-2095.

87. Luo, W.; van der Veer, W.; Chu, P.; Mills, D.; Penner, R. M.;

Hemminger, J. C., The Journal of Physical Chemistry C 2008, 112 (31), 11609-11613.

88. Tian, H.; Chen, H.-Y.; Gao, B.; Yu, S.; Liang, J.; Yang, Y.; Xie, D.;

Kang, J.; Ren, T.-L.; Zhang, Y.; Wong, H. S. P., Nano Lett. 2013, 13 (2), 651 657. 


\author{
CURRICULUM VITAE \\ Amareshwari Konutham \\ Department of Chemistry \\ University of Louisville, \\ Louisville, KY 40292 \\ Email: amareshwari.konutham@gmail.com \\ Contact: +1408-887-8999
}

EDUCATIONAL QUALIFICATIONS:

University of Louisville (Louisville, KY)

M.S. in Chemistry

Advisor: Dr. Francis P Zamborini

(2014-Current)

Jawaharlal Nehru Technological University Hyderabad (Hyderabad, India) M.Sc. (Drugs \& Pharmaceuticals)

(2010-2012)

Osmania University, Hyderabad (Hyderabad, India)

B.Sc. (Microbiology, Biochemistry \& Chemistry)

$(2007-2010)$

\title{
RESEARCH EXPERIENCE:
}

Title: Controlled Electrochemical Synthesis of Single One-Dimensional Metal Nanochains Across Microgap Electrodes (2014- Current)

Under the guidance of Dr. Francis P. Zamborini, Department of Chemistry, University of Louisville, Kentucky, USA.

\section{Description:}

Studied the electrodeposition of silver nanoneedles and nanoparticle film (Ag $\mathrm{NP}$ ) deposition and chains formed at microelectrode gaps upon application of voltage using Two Electrode Devices (TED). Single chains are formed across the electrode gaps by monitoring the current-time plots at $1 \mathrm{~V}$. Morphologies of Ag NP chains formed with controlled current levels have been synthesized and characterized using SEM. Previously, studied the role of humidity for formation of Ag NP chains. This study gave us very important information about the 
relation between humidity and applied voltage to form chains. The relation is inversely proportional. As the level of humidity increases, voltage to form chains decreases. Also, learnt to perform surface-enhanced Raman studies of 4Amino Thiophenol on Ag NP chains. Characterization of the devices was done using scanning electron microscopy, electronic measurements, and Raman spectroscopy.

Title: Synthesis of Graphene using Thermal Chemical Vapor Deposition. (2012 - 2014)

Under the guidance of Dr.V.Himabindu, Center For Alternative Energy Options, Center For Environment, Institute of Science \& Technology, Jawaharlal Nehru Technological University Hyderabad.

\section{Description:}

Graphene is a one-atom-thick two-dimensional layer of carbon with excellent electrical, mechanical, and thermal properties. Chemical vapor deposition is known to be a promising method for the growth of graphene on metal substrates. The work includes the optimization of process parameters such as temperature, hydrocarbon source to inert gas ratio with respect to substrate in Chemical vapor deposition pilot plant level.

\section{Title: Adenosine deaminase activity as a immunoenzyme marker in diabetes} mellitus. (2009)

Under the guidance of Dr. M. Shiva Prakash, National Institute of Nutrition, Hyderabad at Vasundara Biotech Research Institute.

\section{Description:}

The project work includes the study of Adenosine deaminase as an immunoenzyme marker in Diabetes mellitus and the effect of diet on the levels of adenosine deaminase and sugar in the blood using method of Giusti and Trinders method respectively.

\section{TEACHING EXPERIENCE: (August, 2014 - Current)}

Had been working as a Teaching Assistant for more than two years in Department of chemistry UofL. My responsibilities included

- Carrying out laboratory sessions,

- Student consultations and performance evaluations.

- Grading and assessment for 20-25 students/class.

Taught four analytical courses which are the main analytical laboratory courses for undergraduates. The courses mainly included 
CHEM 207 and CHEM 208: Introduction to Chemical Analysis I \& II

- Gravimetric analysis

- Titrations: Acid Base, Redox, Chelation \& Back titrations.

- Spectrophotometry: Measuring transmittance, absorbance, and Beers law.

- Intro to statistics: significant figures, types of errors, accuracy, precision, t-test, Q-test.

- Atomic emission spectroscopy.

CHEM 209 and CHEM 210: Introduction to Chemical Analysis III \& IV

- $\mathrm{pH}$ metric titrations

- Potentiometric titrations

- Atomic Absorption Spectrophotometer

- Gas chromatography.

\section{PUBLICATIONS:}

\section{Applied Surface Science}

Title: Facile soot free approach toward synthesis of carbon nanoropes via chemical vapor deposition of acetylene in the presence of MnFe2O4 coated on stainless steel

Vivek Dhand, S. Bharadwaj, K. Amareshwari, V. Himabindu, Kyong Yop Rhee, Soo-Jin Park, David Hui, Vol. 359, 2015, 797-804.

International Journal of Innovation and Applied Studies.

Title: Flame Synthesis of Carbon Nanorods with / without catalyst.

M. Venkateswer Rao, K. Amareshwari, V. Viditha, C. Mahender, V Himabindu, and Y Anjaneyulu, Vol. 3 (1), 2013, pp. 1-5.

POSITIONS OF RESPONSIBILITY:

\begin{tabular}{|l|l|l|}
\hline Organization & Year & Position \\
\hline $\begin{array}{l}\text { National Seminar on Recent Advances in } 2011 \\
\text { Chemistry, Department of Chemistry, CEH, }\end{array}$ & Souvenir Committee \\
\hline $\begin{array}{l}\text { International Conference on Advances in } 2012 \\
\text { Conference on Advances in Bioloaical } \\
\text { Production, Institute of Science and }\end{array}$ & Organizing Committee \\
\hline
\end{tabular}


Has volunteered

- Intercollegiate Science Festival Constellation for two consecutive years in 2007 \& 2008 by St. Francis College for Women.

\section{CONFERENCES AND WORKSHOPS ATTENDED:}

- Theme meeting on "Recent Advances in Materials Characterisation by Surface Analytical Techniques" organized by National Center for Compositional Characterization of Materials (NCCCM), BARC, Hyderabad on $20^{\text {th }}-22^{\text {nd }}$ February, 2014.

- Awareness workshop on "Intellectual Property Rights" by Patent Information Cell (PIC), JNTUH and Andhra Pradesh State Council of Science and Technology (APCOST) at JNTUH on 26 ${ }^{\text {th }}$ March, 2014.

- "National Workshop on Recent Advances in Science and Technology" by Institute of Science and Technology, JNTUH, Hyderabad on $5^{\text {th }}$ March, 2014.

\section{TECHNICAL SKILLS:}

- Instruments: ICP, GC-MS, HPLC, AAS, RAMAN, SEM, UV \& Visible Spectrophotometer, FT - IR, other chromatographic Analysis, Instrumental Titrimetric analysis.

- Electrochemical Techniques: Cyclic voltammetry, chronocoulometry \& Chronoamperometry.

- Theoretical and Elucidation: H1 NMR, C13 NMR, and TEM.

- Molecular Biology Techniques: Gel Electrophoresis, Amplification of DNA by PCR, Isolation \& Purification of Plasmid DNA.

\section{REFERENCES}

Dr. Francis P Zamborini (Ph. D. Advisor and Professor)

Director of Graduate Studies

Department of Chemistry

University of Louisville

502-852-6550

f.zamborini@louisville.edu

\section{Dr. Richard P Baldwin}

Department of Chemistry

University of Louisville

Phone: 502-852-7061

\section{Rick.baldwin@louisville.edu}

